\title{
HOW TO DO THINGS WITH SIGNS: SEMIOTICS IN LEGAL THEORY, PRACTICE, AND EDUCATION
}

\author{
Harold Anthony Lloyd *
}

\section{INTRODUCTION}

Discussing federal statutes, Justice Scalia tells us that "[t]he stark reality is that the only thing that one can say for sure was agreed to by both houses and the president (on signing the bill) is the text of the statute. The rest is legal fiction." 1

How should we take this claim? If we take "text" to mean the printed text, that text without more is just a series of marks. Agreement on a series of marks without more has no meaning in itself. In struggling with Justice Scalia's remarks, we thus must ask whether on the face of these remarks he has committed the fallacy of conflating signifiers of meaning with meaning itself. Legislators do not agree simply on certain ink marks but on what they believe those ink marks signify. ${ }^{2}$ Their duty is to legislate, not to produce mere marks of ink.

If we instead take "text" to embody something off the page, such as the "meaning" of the series of marks at issue, what is that meaning and how do we know that all the legislators "agreed" on that "meaning"? The series of marks itself cannot prove such unanimity, much less any specific meaning. Even if we take such off-the-page text as referring to words with standard or dictionary meanings, we know that words have multiple such meanings ("left," for example, can mean, among other things, a direction or the past tense of "leave"). A series of marks referring to a series of words in itself thus does not tell us which standard meanings were in the heads of legislators when they read (if they did) drafts of the bill. ${ }^{3}$

* Professor of Law, Wake Forest University School of Law. The title of this Article pays homage to J.L. AUSTIN, How To DO THINGS WITH WORDS (Harvard Univ. Press 1975). I would like to thank my research assistants Laura Jordan and Blake Davis for their careful review and comments. Any shortcomings are of course my own.

1. ANTONIN SCALIA \& BRYAN A. GARNER, READING LAW: THE INTERPRETATION OF LEGAL TEXTS 376 (2012).

2 . Justice Scalia no doubt understands that the meaning is not in the ink itself. He, for example, allows for the correction of scrivener's errors in certain cases. Id. at 234-39. He also acknowledges the role of context in determining meaning. See id. at 16, 20,33. However, he would restrict use of such critical context as legislative history. Id. at 369-90.

3. Thus, we would also want to question Justice Scalia's claim that "a majority [of legislators] has undeniably agreed on the final language that passes into law. That is all they have agreed on ...." SCALIA \& GARNER, supra note 1 , at 393 . 
In struggling with Justice Scalia's claim, we have necessarily delved into semiotics (i.e., the "general theory of signs" 4 ) by noting that meaningful ink marks signify a meaning beyond themselves. The meaning is thus not in the ink but in what the ink signifies. As discussed below, a meaningful ink mark is a "signifier" of meaning (the "signified").

As this example shows, understanding how signifiers of signs function is critical to good judging and lawyering. We risk error if we look only at the signifiers which have no meaning in themselves apart from what they signify. Our task instead is to seek the signified, which, again, lies beyond the signifier. ${ }^{5}$

Additionally, a failure to understand how signs function can limit legal analysis and rhetoric by focusing on words to the detriment of other signs. As we shall see below, words are just one type of sign, and legal analysis and rhetoric are therefore greatly impoverished if we ignore other sign types. Consistent with such impoverishment, we often hear that words are the lawyer's tools. Rather than words alone, this Article will claim that signs in their vast array (including, but not limited to, words) are the lawyer's fundamental tools. ${ }^{6}$

This Article therefore broadly explores semiotics through a lawyer's lens, hopefully simplifying as much as possible much of the complex, divergent, and, frankly, sometimes baffling terminology used by those who explore semiotics. This Article will first continue below with a general definition of signs and the related notion of intentionality. It will then address the structure and concomitants of signs; the nature of speech acts that are of interest to lawyers; the sign classifications used in legal analysis and rhetoric; the role of signs in careful legal thought and good legal rhetoric; the unfolding of the signified and the fixation of meaning debate; the semiotics of speaker vs. reader meaning; and some brief reflections on semiotics and the First Amendment. Finally, this Article also provides an Appendix with further terms and concepts helpful to lawyers exploring semiotics.

I hope this Article's broad overview of semiotics underscores the vital importance of semiotics in law and in legal education reform. I also hope this Article inspires readers and legal education reformers to explore the vast worlds of semiotics that elude the page constraints of a general overview.

4. Charles Morris, Signification AND SignificAncE: A STUDY OF THE RELATIONS OF SIGNS AND VALUES 1 (1st ed. 1964).

5. I have challenged naïve textualism elsewhere and will therefore not explore that specific issue in detail in this Article. See generally Harold A. Lloyd, Law's "Way of Words": Pragmatics and Textualist Error, 49 CREIGHTON L. REV. 221 (2016).

6. Signs are, of course, all others' tools as well. As Charles Sanders Peirce notes, and as I hope this Article will help demonstrate "the universe ... is perfused with signs, if it is not composed exclusively of signs." 5 \& 6 CHARLES SANDERS PEIRCE, COLLECTED PAPERS OF CHARLES SANDERS PEIRCE 5.448 n.1 (Charles Hartshorne \& Paul Weiss eds., 1963). 


\section{Definition And Function of Signs, SEmiotics, AND RELATED TERMS}

Given the many interrelated parts of semiotics, one must make a judgment call as to where to begin. My judgment call is to begin with the definition of a sign and to build from there.

\section{A. Definition of Sign}

A "sign" consists of a co-related signifier and signified, where the signifier is used to "represent" "something else," 7 i.e., the signified. ${ }^{8}$ Or as Eco puts it, "The sign is usually considered as a correlation between a signifier and a signified (or between expression and content) and therefore as an action between pairs." 9 Thus, one might use the word "monarch" (the signifier) to signify a certain butterfly (the signified). In such a case, their co-relation as signifier and signified would thus be a sign. I explore in more detail in Part II the nature and interrelation of a signifier and a signified.

One should take care at the outset not to confuse "signs" (i.e., corelations of signifiers and signifieds as discussed above) with just the "signifiers" involved. Such confusion is all too easy in ordinary language. For example, we might speak of a stop "sign" at an intersection. However, semiotically speaking, that physical object is a signifier of an obligation to stop, and the sign involved here is the co-relation of such signifier and the obligation to stop to which that signifier refers. This is the same relation that we saw, again, in the sign involving the word "monarch" as signifier and the butterfly as signified. Unfortunately, in semiotic literature, the term "sign" can be used for "signifier,"10 and

7. See 1 \& 2 ChARLES SANDERS PEIRCE, COLlECTED PAPERS OF CHARLES SANDERS PEIRCE 2.27-2.32 (Charles Hartshorne \& Paul Weiss eds., 1960). In Peircean terms, a signifier can also be said to be "something which stands to somebody for something in some respect or capacity." Id. at 2.228.

8. Not everyone agrees with the two-part structure of signs adopted here. For a brief table of various conceptions of the basic structure of signs, see WINFRIED NÖTH, HANDBOOK OF SEMIOTICS 88 (1995).

9. UMBerto ECO, SEMIOTICS AND THE PhilOSOPHY OF LANGUAGE 1 (Ind. Univ. Press 1984).

10. For example, Clarke tells us that "[a] sign is any object of interpretation, a thing or event that has significance for some interpreter. It can stand for some object for this interpreter, signify an action to be performed, arouse in the interpreter a feeling or emotion, or combine two or more of these functions." D.S. CLARKE, JR., SOURCES OF SEMIOTIC: READING WITH COMMENTARY FROM ANTIQUITY TO THE PRESENT 1 (1990). Peirce speaks more carefully in the following passage: "A sign, or representamen [i.e., signifier], is something which stands to somebody for something in some : . capacity." 1 \& 2 PEIRCE, supra note 7 , at 2.228. However, elsewhere, he is not so careful. See id. at 2.230. Peirce notes that "in order that anything should be a Sign, it must 'represent,' as we say, something else, called its Object . . .."Id. 
the reader must therefore take care when reading such literature to substitute "signifier" for "sign" where appropriate. ${ }^{11}$

\section{B. Signs and Intentionality}

Since signs involve signifiers that point to something else, signs involve what philosophers call "intentionality." Intentionality recognizes that "[o]ur beliefs, thoughts, wishes, dreams, and desires are about things," and intentionality is thus "[t]he directedness or 'aboutness' of many, if not all, conscious states." 12 As John R. Searle defines the term, "Intentionality is that property of many mental states and events by which they are directed at or about or of objects and states of affairs in the world." 13 Intentionality also includes "the property of mental phenomena whereby the mind can contemplate non-existent objects and states of affairs." 14 Thus, "I will have your lease ready tomorrow" is intentional to the extent it signifies a lease (presently existing or not) that will be ready tomorrow.

In addition to intentional states such as "[b]eliefs, fears, hopes, and desires" that are intentional in themselves (since they are mental states directed outward), intentionality can flow derivatively from the mind as well as the intention by which an act is performed. ${ }^{15}$ For example, a legal drafting computer program can include signifiers that signify because someone has constructed the program with such intention. ${ }^{16}$ A computer program (such as a legal software program) can also have intentionality when someone reads it as signifying something. ${ }^{17}$ The divergence of speaker and hearer meaning can be of great importance for lawyers, and I discuss and contrast speaker and reader meaning (as well as whose meaning should control) in Part VI below.

Whether we focus on speaker or hearer meaning in the case of text, for example, such meaning cannot, of course, be simply equated with the ink marks on a page. Without more, such marks are just that-ink upon a page. Such ink marks take on intentionality when we (as speaker or hearer) use and interpret such marks to represent or point beyond themselves. Thus, Charles Sanders Peirce tells us that "[t]he

11. See also NöTH, supra note 8, at 79 (also discussing such confusion in the literature).

12. See Intentionality, OXFORD DICTIONARY OF PHILOSOPHY (3d ed. 2016).

13. JOHN R. SEARLE, INTENTIONALITY: AN ESSAY IN THE PHILOSOPHY OF MIND 1 (1983).

14. Intentionality, PENGUIN DiCTIONARY OF PHILOSOPHY (2d ed. 2005).

15. See SEARLE, supra note 13, at 27-29 (on derived intentionality).

16. See also Thomas A. Sebeok, The Doctrine of Signs, in FRONTIERS IN SEMIOTICS 35, 36 (John Deely et al. eds., 1986) ("Any source and any destination [of signs], is a living entity or the product of a living entity, such as a computer....").

17. Again, Peirce tells us that "[a] sign, or representamen [i.e., signifier], is something which stands to somebody for something in some ... capacity." 1 \& 2 PEIRCE, supra note 7 , at 2.228 . 
Sign creates something in the Mind of the Interpreter," 18 and "nothing is a sign unless it is interpreted as a sign." 19 Thus, Eco also tells us that a "sign is not only something which stands for something else; it is also something that can and must be interpreted." ${ }^{20}$ I further address interpretation (including whose interpretation controls in certain situations) as the Article progresses. I also contrast interpretation and construction in section VI.B.1 below.

\section{Definition of Semiotics}

Having defined signs, we can now define "semiotics." Charles Morris provides a useful definition: "Semiotic[s] has for its goal a general theory of signs in all their forms and manifestations, whether in animals or men, whether normal or pathological, whether linguistic or nonlinguistic, whether personal or social. Semiotic is thus an interdisciplinary enterprise." 21

Although Morris uses the term "semiotic," I follow Sebeok and use the term "semiotics," which Sebeok notes has "made irreversible inroads over" the term "semiotic" in American English. ${ }^{22}$

As a general and interdisciplinary theory of signs which covers how we signify and how we interpret experience, semiotics is thus a vast enterprise. As Sebeok tells us, "what semiotics is finally all about is the role of the mind in the creation of the world or of physical constructs out of a vast and diverse crush of sense impressions." ${ }^{23}$ Good lawyers can hardly fail to have a good grasp of such an enterprise.

18. 8 CHARLES SANDERS PEIRCE, COLLECTED PAPERS OF CHARLES SANDERS PEIRCE 8.179 (Arthur W. Burks ed., 1958).

19. $1 \& 2$ PEIRCE, supra note 7 , at 2.308 . We can thus use intentionality to parse between signifiers and non-signifiers. For example, an unobserved tree may have a patch of bark that cracks in the form of "m." That crack in the bark is not a signifier of mathematical pi (or any other pi) unless some mind uses or perceives that crack in the bark as signifying pi or as otherwise having such mathematical meaning. I have an express purpose in using "mind" here rather than "person" when referring to such intentionality. Although beyond the scope of this Article, I am sympathetic with the field of zoosemiotics, which explores animals and semiotics. See Sebeok, supra note 16, at 76 (Zoosemiotics "focuses on messages given off and received by animals, including important components of human nonverbal communication, but excluding man's language and his secondary, language-derived semiotic systems, such as sign language or Morse code.").

20. ECO, supra note 9, at 46.

21. MORRIS, supra note 4 , at 1 .

22. Thomas A. Sebeok, "Semiotics" and Its Congeners, in 1 LINGUISTIC AND LITERARY STUDIES 283, 288 (Mohammad Ali Jazayery et al. eds., Mouton Publishers 1978).

23. Sebeok, supra note 16 , at 42. 


\section{Structure AND Concomitants of Signs In More DetaIL}

With the above preliminaries addressed, we can now turn in more detail to the structure of signs. In what follows, I shall use Eco's description of a sign as "a correlation between a signifier and a signified (or between expression and content) and therefore as an action between pairs."24 As such, I shall distinguish and explore the signifier and the signified as correlated in the sign.

\section{A. The Signifier}

When lawyers think of signifiers, they often think of either written text (as with the Justice Scalia example above) or spoken words (as, for example, in a jury instruction). One of the goals of this Article is to expand lawyers' views of the vast expanse of possible signifiers beyond text and spoken words. I will give a concrete example of the importance of such expansion in section IV.B below, where I briefly explore, as an exemplar for lawyers, Marc Antony's use of multiple types of signifiers. In performing such expiration, I hope lawyers will take to heart Langer's assertion that "[l]anguage is by no means our only articulate product." 25 When analyzing signifiers, we must remember that they can include such a wide array as a "concrete object," "an abstract entity," "an idea or "thought," a "perceptible object," a "physical event," or an "imaginable [object]." 26 I explore signifier types further in Part III, where I explore the indexical, iconic, and symbolic signifier types that lawyers and others can encounter and use.

\section{B. The Signified}

Since the same person, place, thing, or event can have multiple meanings (my nephew is also my brother's son), the signified can involve both sense (the cognitive or mental component of meaning) and reference (that to which the term refers as fact-such as the earth revolving around the sun-or fiction, such as Pegasus flying around the earth). ${ }^{27}$ Meaning has a sense component to account for the different meanings the same person, place, or thing may have. Meaning has a reference component to tie meaning to the specific portions of the ob-

24. ECO, supra note 9, at 1 .

25. Susanne K. Langer, Discursive and Presentational Forms, in SEMIOTICS: AN INTRODUCTORY ANTHOLOGY 87, 96 (Robert E. Innis ed., 1985).

26. See NÖTH, supra note 8 , at 80 ; see also $1 \& 2$ PEIRCE, supra note 7 , at 2.230 (failing to parse between "sign" and "signifier" in discussing the "perceptible" and the "imaginable").

27. See NÖTH, supra note 8, at 92-100. The signified may involve only reference when, for example, it refers to the pre-semantic which has not yet been put to words or otherwise given sense. See Harold A. Lloyd Making Good Sense: Pragmatism's Mastery of Meaning, Truth, and Workable Rule of Law, 9 WAKE FOREST J. L. \& POL'Y 199, 208-09'(2019). 
jective or fictional world of experience and to tie together the different senses those specific portions may have. ${ }^{28}$ Thus, for example, reference ties "my nephew" and "my brother's son" into the same person. Careful lawyers will grasp both suitable referential aspects of meaning in play as well as suitable sense.

\section{Reference and the Referent}

\section{a. Definition of Referent}

The referent is that to which a signifier refers as fact or fiction. ${ }^{29}$ Again, for example, it is the single person referred to by both "my nephew" and "my brother's son."

Lawyers should remember that when we meaningfully refer with our signifiers, we are referring within the context of experience as we have interpreted it in our webs of signs (unless we would refer, without more, to the yet-to-be interpreted). ${ }^{30}$ When referring within such interpreted experience, we are thus not referring to unknown or transcendentally-fixed things-in-themselves. Instead, we are referring to "things" within our semantic lifeworlds ${ }^{31}$ woven out of our webs of signs. Since we weave our webs of signs, such webs of signs and the "things" within them are not transcendentally given and we can thus revise our referents to the extent pre-semantic and semantic restraints allow. ${ }^{32}$

Lawyers should remember this critical nature of reference because it permits progress. Since reference (other than reference without more to the yet-to-be interpreted) occurs within our semiotics and is thus not transcendentally given, and since any reality to which we refer is thus "internal" to our semantic lifeworlds, ${ }^{33}$ we can always have hope of changing reference where progress requires. Thus, for example, since the referent of marriage is not transcendentally fixed, we can point out its referent with definite descriptions ${ }^{34}$ that do not limit the referent to

\footnotetext{
28. See NÖTH, supra note 8, at 92-100.

29. See Reference, PENGUIN DICTIONARY OF PHILOSOPHY ( $2 \mathrm{~d}$ ed. 2005).

30. Lloyd, supra note 27, at 208-09.

31. See infra APPENDIX for a brief outline of the term "lifeworld" and related terms.

32. See Lloyd, supra note 27, at 206-10, 222-44, 264-74 where I discuss in detail the freedoms and restraints on change.

33. See id; see also HILARY PUTNAM, REALISM WITH A HUMAN FACE 114 (James Conant ed., 1992) (the internal realist "is willing to think of reference as internal to 'texts' (or theories), provided we recognize that there are better and worse 'texts.' 'Better' and 'worse' may themselves depend on our historical situation and our purposes; there is no notion of a God's-Eye View of Truth here ....").

34. The referent of marriage here is an institution whose sense has unfolded in experience as discussed in this Article. By "definite descriptions," I mean a "description of a (putative) object as the single, unique, bearer of a property: 'the smallest positive number'; 'the first dog born at sea'; 'the rich-
} 
heterosexual unions (much like we can point out the referent of earth with definite descriptions that do not involve older descriptions such as the flat surface at the center of the universe). ${ }^{35}$ As I have written elsewhere, re-describing commonly-accepted aspects of lifeworlds can face considerable pushback, but lawyers have a duty to resist such pushback where moral or other experience (or both) require. ${ }^{36}$ The same duty applies to the "sense" component of meaning discussed in more detail below.

\section{b. Reference Difficulties for Lawyers and Others}

Forgetting that references are not transcendentally fixed is thus a first-order error of reference. Where references in our semantic lifeworld are wrong or wrongly determined by definite descriptions as in the case of marriage or earth as discussed above, forgetting that such error is at most "mind-forged manacles" 37 that we might break is a tragedy of the highest order for lawyers and their clients.

A second-order error of reference stems from the act of referring itself. When a client, for example, would refer to something whose ownership she disputes with her sibling (such as a diamond money clip to which she points), problems can arise from the mechanics of reference itself. From the outset, lawyers should know that mere pointing alone never works as a clear indication of reference. For how can pointing in itself determine the multiple possible referents to which we point in any case? For example, if we point at a person, are we pointing at the whole person, the person's head, the person as a person of a certain type, the place where person is standing, the direction in which the person stands, and so on? As Wittgenstein thus notes, when one wishes to name a person by pointing at the person, the viewer might instead take that act as pointing to ". . . a colour, ... a race, or even of a point of the compass." 38

est person in the world." Definite Description, OXFORD DICTIONARY OF PHILOSOPHY (3d ed. 2016).

35. Philosophers do not agree on how reference works. See Referring, THE OXFORD COMPANION TO PHILOSOPHY (Ted Honderich ed., 2d ed. 2005) "IIntuitively, for an expression to refer is for it to stand for or pick out something, but what this involves has been long debated. According to Frege the reference of an expression is determined by its sense, but lately Kaplan and Kripke have argued that some terms such as demonstratives, proper names, and natural-kind terms, refer directly."). Lawyers do not have the luxury of debate here and must make reference work in their discussions with clients and others. Proper names where applicable "like 'Julius Caesar' or definite descriptions like "the conqueror of Gaul" seem to me sounder ways to start. See Reference, PENGUIN DICTIONARY OF PHILOSOPHY (2d ed. 2005).

36. See, e.g., Lloyd, supra note 27, at 264-74 (discussing "workability" to avoid presemantic and semantic pushback).

37. See WILLIAM BLAKE, London, in SONGS OF INNOCENCE AND EXPERIENCE WITH OTHER POEMS 65, 65 (Basil Montagu Pickering 1866).

38. LUDWIG WiTTGENSTEIN, PhILOSOPHICAL INVESTIGATIONS 13-14 (G. E. M. Anscombe et al. trans., Macmillan Co. 3d ed. 1968). 
In the hypothetical above, perhaps the client is only pointing to one of the diamonds in the money clip rather than to the money clip itself. Perhaps the sibling does not care about that diamond and would be satisfied with the rest of the money clip. The lawyer would be welladvised here to inquire in more depth as to the client's reference. Otherwise, the parties may have an unnecessary lawsuit.

Reference can also be further complicated here by imprecision on the client's part. The client may actually speak of the entire money clip though she only really wants the diamond. Her lawyer must thus not only seek precision as to her expressed reference but also seek clarity as to her real reference. As I have discussed the need for careful reference in detail elsewhere, ${ }^{39} \mathrm{I}$ will not discuss the matter further here.

\section{Sense}

\section{a. Overview}

With the understanding that "experience" includes external experience (i.e., public or objective experience) as well as internal experience (i.e., private ${ }^{40}$ experience such as thoughts, imagination, memories, and feelings ${ }^{41}$ ), in defining "sense" I shall use the following modified version of Charles Sanders Peirce's early pragmatic notion of meaning: the sense of a particular concept is the total actual and possiblyconceivable ${ }^{42}$ ways in which that concept unfolds or can unfold in such experience. ${ }^{43}$ Thus, for example, the different senses of "President of the Senate" and "Vice President" (both of which refer to the same per-

39. See Harold A. Lloyd, Plane Meaning and Thought: Real-World Semantics and Fictions of Originalism, 24 S. CAL. INTERDISC. L.J. 657, 680-83 (2015).

40. By private experience, I mean experience private to the individual such as (without limitation) a thought or pleasant or painful sensation.

41. This is thus broader than "synthesis, imagination, memory, evaluation and estimation" which Deely calls the "internal sense in philosophical tradition.” JOHN DEELY, INTRODUCING SEMIOTIC: ITS HISTORY AND DOCTRINE 98 (1982).

42. Again, this can include private experience. "Possible" incorporates a normative as well as factual sense. For example, it is not possible in common speech for a typical dog to have ten legs.

43. Peirce's formula reads: "Consider what effects, that might conceivably have practical bearings, we conceive the object of our conception to have. Then, our conception of these effects is the whole of our conception of the object." 5 \& 6 PEIRCE, supra note 6, at 5.402. To the extent Peirce's formula focuses only. on objective experience and therefore results in beliefs being synonymous if they cause the same habits, I would disagree. See JoHN P. MURPHY, PRAGMATISM: FROM PEIRCE TO DAVIDSON 25-26 (1990). For example, after hearing a knock, I could have a habit of walking across my office to the door in just the same way whether I believe that a student or another professor is at the door. See also WILLIAM JAMES, PRAGMATISM: A NEW NAME FOR SOME OLD WAYS OF THINKING 18 (Thomas Crofts \& Philip Smith eds., Dover Publ'ns, Inc. 1995) (1907) (setting out James's interpretation of Peirce's notion of meaning). 
son) depend upon the different ways such notions play out in such experience. ${ }^{44}$

I choose this approach to sense for at least two reasons. First, if sense does not come through either external experience (i.e., public or objective experience) or through internal experience (i.e., private experience such as thoughts, imagination, memories, and feelings), how could we possibly know it or relate it to the world of our external or internal experience? Second, and consistent with the first reason, this notion of sense fits how we understand sense in court, in the practice of law, in law school, and in life. If one asks good lawyers, for example, what an actual or proposed liability limitation in a contract means, such lawyers would "flesh it out" and would describe how the liability limitation would play out in practice. These reasons are compelling in themselves, and I will therefore not explore in this Article difficulties with other current accounts of meaning and sense that I have discussed elsewhere (such as meaning as reference alone, meaning as merely ideas, behaviorism, and meaning as truth conditions)..$^{45}$ Con-

sistent with the experiential definition I have used of "sense," the signified may, however, be much less complex than how a proposed liability limitation in a contract might play out in experience. In some cases, the signified might simply be a feeling (or at least at first just a feeling). Peirce, for example, tells us that "[t]he first proper significate effect of a sign is a feeling produced by it. There is almost always a feeling which we come to interpret as evidence that we comprehend the

44. Such experience can include connotation, or the "socio-cultural and personal associations," attached to the signifier or the signified. See DANIEL CHANDLER, SEMIOTICS: THE BASICS 246 (2d ed. 2007).

45. See Harold A. Lloyd, Exercising Common Sense, Exorcising Langdell: The Inseparability of Legal Theory, Practice and the Humanities, 49 WAKE FOREST L. REV. 1213, 1250-54 (2014). Additionally, C.K. Ogden \& I.A. Richards outline no less than sixteen broad approaches to meaning (with some approaches having various subdivisions). In this outline, meaning can be: "I An Intrinsic property. II A unique unanalysable Relation to other things. III The other words annexed to a word in the Dictionary. IV The Connotation of a word. V An Essence. VI An activity Projected into an object. VII (a) An event intended. (b) A Volition. VIII The Place of anything in a system. IX The Practical Consequences of a thing in our future experience. [This comes closest to my definition, although I would include past experience and am careful to include both external and internal experience as above defined.] X The Theoretical consequences involved in or implied by a statement. XI Emotion aroused by anything. XII That which is Actually related to a sign by a chosen relation. XIII (a) The Mnemic effects of a stimulus. Associations required. (b) Some other occurrence to which the mnemic effects of any occurrence are Appropriate. (c) That which a sign is Interpreted as being of. (d) What anything Suggests. In the case of symbols. That to which the User of a Symbol actually refers. XIV That to which the user of a symbol Ought to be referring. XV That to which the user of a symbol Believes himself to be referring. XVI That to which the Interpreter of a symbol (a) Refers. (b) Believes himself to be referring. (c) Believes the User to be referring." C.K. OGDEN \& I.A. RICHARDS, THE MEANINGG OF MEANING 186-87 (1923). If we are to know any such meaning, I would simply ask how such meaning could be separated from "experience" as I have defined it. Such a return to experience as I have defined it, of course, returns us to my proposed definitions of meaning and sense. 
proper effect of the sign, although the foundation of truth in this is frequently very slight." 46

Signs can also produce a feeling that something is not right. For example, the word "slave" might invoke to Huck Finn a certain extreme malaise that he cannot put into words in his current vocabulary. As I have argued elsewhere, such feeling can play an important role in our interactions with the world, as with Huck's decision to help liberate a slave even though his concepts and categories of the time told him that was wrong. ${ }^{47}$ Lawyers, too, should of course listen to their feelings when, for example, a proposed text or course of action does not feel right.

The signified can be feelings of other kinds as well. For example, Peirce believes that "the performance of a piece of concerted music is a sign. It conveys, and is intended to convey, the composer's musical ideas; but these usually consist merely in a series of feelings." 48

Thus, when I refer to "experience," I refer along with Deely to "the whole of our experience, from its most primitive origins in sensation to its most refined achievements of understanding" and thus to a "network or web of sign relations." 49 I also agree with Deely that "experience reveals itself as a constructed network built over time both through [our] biological heritage ... and through the individual experiences whereby, atop the biological heritage, socialization and enculturation transpire." 50

Finally, lawyers should remember that sense, like reference, is not transcendentally fixed. ${ }^{51} \mathrm{We}$ can and should adjust our sense as moral or other experience (or both) demands. For example, where moral or other experience (or both) require correction of the dehumanizing of homosexuals, lawyers should work against such dehumanization. No matter how old the pedigree of such dehumanization, such dehumanization is not transcendentally fixed ${ }^{52}$ and can therefore be combatted and corrected no less than notions, again, that once held that the Earth is flat and at the center of the universe. Once more, however, lawyers must be aware of the strong pushback that may occur when commonly-held meanings and categorizations are challenged in lifeworlds and strategize accordingly. ${ }^{53}$

46. 5 \& 6 PEIRCE, supra note 6 , at 5.475 .

47. See Harold A. Lloyd, Cognitive Emotion and the Law, 41 L. \& PSYCHOL.

REV. 53, 62-63 (2016); Lloyd, supra note 27, at 225-26.

48. $5 \& 6$ PEIRCE, supra note 6 , at 5.475 .

49. JOHN DEELY, BASICS OF SEMIOTICS 13 (1990).

50. Id. at 14 .

51. See Lloyd, supra note 27, at 210-22.

52. See id.

53. See id. at $227-43$. 


\section{b. Sense and "Dimensions of Signification"}

With Morris, we can also usefully note a further expansive nature of sense, distinguishing between three "dimensions" of signification: the designative, appraisive, and prescriptive. ${ }^{54}$ Morris thus tells us that the "designative" involves the "Sense organs" and relates to "Obtaining information"; the "appraisive" involves "Object preferences" and relates to the "Selection of objects for preferential behavior"; and the "prescriptive" involves "Behavior preferences" and relates to "Action on object by specific behavior." 55 As examples, he tells us that "usually 'black' is primarily descriptive, 'good' is primarily appraisive, and 'ought' is primarily prescriptive." 56 Morris notes that context can change this result, and in some contexts, "black" can be "primarily appraisive or prescriptive," "good" can be primarily "designative or prescriptive," and "ought" can be "primarily designative or appraisive." 57 Morris also notes that any particular sign may in varying degrees operate in all the dimensions of signification. ${ }^{58}$ Again, therefore, sense may involve more than just communication of fact or fiction. Rather than simply listening to a client's words, a lawyer should, of course, probe the way the client describes and perceives the matter at hand, the way the client appraises the matter at hand, and the way the client would prefer to act. It is hard to see how a lawyer can discern a client's real interests in a matter without exploring Morris's three dimensions of signification. In this regard, one can consider again the diamond money clip dispute discussed in Part II.B.1.b above.

\section{Reference, Sense, and RIRAC: Polishing One Legal Form of Thought}

We can also use the sense and reference dimensions of meaning to polish a common legal form of thought: IRAC. In teaching law students to address all necessary steps in legal analysis, we teach them, among other things, the IRAC form, which stands for "Issue," "Rule," "Application," and "Conclusion." 59 Using IRAC as both a form and as a checklist, students and lawyers can both improve the logical flow of their analysis and check for omissions in their analysis. As to logical flow, resolving legal issues requires finding the rules that govern such issues, applying such rules, and reaching a conclusion. As to IRAC as a checklist, it reminds students and lawyers to identify and explore fully the issue or issues in play, to fully research and explore the rules in

54. MORRIS, supra note 4 , at 4 .

55. Id. at 8 .

56. Id. at $4-5$.

57. Id. at 5 .

58. Id.

59. CHRISTINE COUGHLIN, JOHN MALMUd ROCKLIN \& SANDY PATRICK, A LAWYER WRITES: A PRACTICAL GUIDE TO LEGAL ANALYSIS 94 (3d ed. 2018). 
play, to fully and expressly apply those rules in play (a step that requires constant reminder given the tendency to assume readers also know all the application steps that are in the student's or lawyer's head), and to provide the appropriate conclusion in a way that makes sense to the reader.

IRAC is thus quite useful as far as it goes. However, its focus on issues, rules, applications, and conclusions is a focus on the sense aspect of meaning. As we have seen that meaning involves both reference and sense, IRAC safely works only where there is no dispute or confusion as to reference. As we saw with the diamond money clip above, assuming no dispute or confusion as to reference can be quite dangerous. I therefore teach students that they should remember, in actual law practice at least, the more expansive checklist of RIRAC, with the first "R" standing for "reference." I, in fact, encourage them to think of RIRAC as one of the most basic forms (if not the most basic form) of checklists, as it is applicable across a wide variety of legal situations. For example, when a client arrives to discuss a dispute (such as a dispute involving the money clip above), the lawyer's first step should be to clarify the reference. If the lawyer, client, or opposing party is confused about the reference, then the issues, rules, applications, and conclusions debated and explored may be irrelevant to the real matter in dispute. As shown by the diamond money clip dispute above, finding such reference can be difficult, but it must be done. Lawyers must have a complete and accurate grasp of the signified, which includes reference as well as sense. Since I have also addressed RIRAC in detail elsewhere, ${ }^{60}$ I will not explore it further here.

\section{Correlation OF Signifier AND Signified AND ThreE ClASSIFICATIONS OF SIGNS}

Having explored both the signifier and the signified, we can now explore their correlation. This should help demonstrate to lawyers the vast expanse of signs available for their use. In what follows, I shall again use Eco's description above of a sign as "a correlation between a signifier and a signified (or between expression and content) and therefore as an action between pairs." 61 Peirce gives us three basic types of correlation (the indexical, the iconic, and the symbolic ${ }^{62}$ ) that are of special interest to lawyers, and I thus briefly explore below the signifier-signified co-relations in indices, icons, and symbols. ${ }^{63}$ Since lawyers

60. See Lloyd, supra note 39, at 669-70.

61. ECO, supra note 9 , at 1 .

62. 1 \& 2 PEIRCE, supra note 7 , at 2.275; PEIRCE, supra note 18, at 8.335.

See also generally 1 \& 2 PEIRCE, supra note 7 , at 2.247-49, 2.275-307.

63. I agree with Chandler that "[a]lthough [this tripartite division of signs] is often referred to as a classification of distinct 'types of signs,' it is more usefully interpreted in terms of differing 'modes of relationship' between [signifiers] and what is signified." CHANDLER, supra note 44 , at 36. 
tend to focus on text and speech (which use symbolic forms of signifiers), I will begin with Peirce's perhaps less familiar types of signs involving indexical and iconic signifiers.

\section{A. Indices}

\section{Correlation of "Real" Relation}

Peirce tells us that "[a]n Index is a sign which refers to the Object that it denotes by virtue of being really affected by that Object," 64 or "by virtue of being in a real relation to it." 65 Chandler usefully expands upon the indexical relation as "a mode in which the signifier is not arbitrary but is directly connected in some way (physically or causally) to the signified (regardless of intention)."66

Peirce gives a number of examples of indices including, the following: a sundial indicating the time, a "rap on the door," "a tremendous thunderbolt [indicating] that something considerable happened," "[a] low barometer with a moist air" indicating rain, a "weathercock" indicating the direction of the wind, "[t]he pole star" indicating north like a "pointing finger," a "plumb bob" indicating the "vertical direction," demonstrative pronouns like "this" and "that" indicating when successfully calling "upon the hearer to use his powers of observation [in order to] establish a real connection between his mind and the object," letters such as "A, B, C, D" used by geometricians to indicate parts of diagrams or used by lawyers and others to "fulfill the office of relative pronouns." 67 Thus, Peirce also tells us that pronouns are indices because "they indicate things in the directest possible way."68 Thus, "[a] pronoun ought to be defined as a word which may indicate anything to which the first and second persons have suitable real connections, by calling the attention of the second person to it." 69 Similarly, indices can also be "more or less detailed directions for what the hearer is to do in order to place himself in direct experiential or other connection with the thing meant." 70 This could include such notices as "there is a rock, or shoal, or buoy, or lightship." ${ }^{1}$ Peirce also both claims that proper names are indices" 72 and that proper names "should probably be regarded as Indices." 73 Short explains Peirce's likely thinking here as fol-

64. 1 \& 2 PEIRCE, supra note 7, at 2.248.

65. See 8 PEIRCE, supra note 18, at 8.335. Peirce uses the term "dynamic object" here.

66. CHANDLER, supra note 44 , at 37.

67. 1 \& 2 PEIRCE, supra note 7, at 2.285-87.

68. Id. at 2.287 n. 1 .

69. Id.

70. Id. at 2.288 .

71. Id.

72. See 8 PEIRCE, supra note 18 , at 8.335.

73. 3 \& 4 CHARLES SANDERS PEIRCE, COLLECTED PAPERS OF CHARLES SANDERS PEIRCE 4.544 (Charles Hartshorne \& Paul Weiss eds., 1980). As an 
lows: "we can say that each replica of the same proper name, e.g., 'Napoleon Bonaparte', signifies whatever earlier replicas signified, going back to its original replicas, assigned, by an act of naming . . .."74 Finally, Peirce notes the role of indices in successful communication. The claim "Why, it is raining!" does not tell us where it is raining; we need either context (such as the speaker's "standing here looking out at a window as he speaks, which would serve as an Index"), or we need the proposition itself to indicate where it is raining. ${ }^{75}$

Noting that the link between signifier and signified "can be observed or inferred," as examples of indices, he lists:

natural signs (smoke, thunder, footprints, echoes, nonsynthetic odours and flavours), medical symptoms (pain, a rash, pulse-rate), measuring instruments (weathercock, thermometer, clock, spirit-level), 'signals' (a knock on the door, a phone ringing), pointers (a pointing 'index' finger, a directional signpost), recordings (a photograph, a film, video or television shot, an audio-recorded voice), [and] personal 'trademarks' (handwriting, catchphrases). ${ }^{76}$

I could, of course, explore in virtually endless detail Peirce's other complex comments on indices (some of which I would challenge). However, my purpose here is to explore semiotics in a form useful to lawyers, and this enumeration of indices should suffice for the notion that indexical relations occur where "the signifier is not arbitrary but is directly connected in some way (physically or causally) to the signified (regardless of intention)." 77

\section{Evidence and Indices}

Many lawyers will no doubt quickly think of evidence when they consider such a notion of the indexical sign. A bloody knife, for example, can be an indexical sign of a stabbing if the knife is directly connected to that stabbing in the way that indexical co-relations require. Rather than a mere academic exercise, understanding the nature and proof of such indexical co-relations is thus of critical importance to lawyers. An indexical bloody knife also reminds the lawyer of the potential power of indexicals over words in such cases. A bloody knife di-

example of the difficulties of parsing out Peirce's actual thought, he also tells us that "a proper name, personal demonstrative, or relative pronoun or the letter attached to a diagram, denotes what it does owing to a real connection with its object but none of these is an Index, since it is not an individual." 1 \& 2 PEIRCE, supra note 7, at 2.284. Again, my purpose here is to provide an overview of semiotics that I believe works and is useful to lawyers; I am not trying to provide an encyclopedic survey of conflicting views between various thinkers and within individual thinkers themselves.

74. T. L. Short, Life Among the Legisigns, in FRONTIERS IN SEMIOTICS 105, 112 (John Deely et al. eds., 1986).

75. See 3 \& 4 PEIRCE, supra note 73 , at 4.544 .

76. CHANDLER, supra note 44, at 37.

77. Id. 
rectly connected with both a stabbing and the person alleged to have committed the stabbing can be much more rhetorically compelling than the victim's words, especially if the stabber disputes the victim's words. I will return to indices in Part IV.B, when I explore the rhetorical indexical force of Caesar's body, bloody toga, and will in Marc Antony's funeral oration for Caesar, and in Part III, when I explore certain indexical claims in the context of the First Amendment.

\section{B. Icons}

\section{Correlation of Similarity}

Peirce tells us that an icon represents "mainly by its similarity."78 Chandler usefully clarifies the co-relation of signifier and signified here as "a mode in which the signifier is perceived as resembling or imitating the signified (recognizably looking, sounding, feeling, tasting or smelling like it) [or] being similar in possessing some of its qualities."79

For Peirce, icons include, without limitation, images, diagrams, pictures, and metaphors. ${ }^{80}$ Peirce also notes that although photographs "are in certain respects exactly like the objects they represent," they obtain this likeness through the physical connections of photography. As such, photographs are indices. ${ }^{81}$ In my view, photographs are both indices and icons and demonstrate how signifiers and their signified can have multiple co-relations.

Peirce points out that resemblance need not turn on appearance. It can also involve resemblance of objects in terms of "the relations of their parts." 82 Diagrams, for example, may set out certain parts of their objects without truly resembling them. ${ }^{83}$

Lawyers may, at first blush, consider icons less useful than indices, because the latter have "real" relations to what they signify. For example, a clear photograph of an alleged criminal stabbing a victim is certainly more persuasive of guilt than a clear drawing of the same act. This initial thought, however, underestimates the value of icons in practice. First, icons can focus only on relevant relations, as in the case of diagrams. ${ }^{84}$ As such, they permit us to study and discover new knowledge from depictions of such relations. ${ }^{85}$ By excluding irrelevant aspects of matters diagrammed, they can perhaps expedite such discovery. Diagrams can also perhaps expedite uncovering error or other

78. 1 \& 2 PEIRCE, supra note 7 , at 2.276 .

79. CHANDLER, supra note 44 , at 36.

80. 1 \& 2 PEIRCE, supra note 7 , at 2.277, 2.279.

81. Id. at 2.281 .

82. Id. at 2.282 .

83. Id.

84. Id

85. See id. at 2.279 . 
difficulties in the matters diagrammed. Second, since icons are untethered from the "real" relations found in photography, they allow rhetorical use not possible with indices such as photographs. ${ }^{86}$ Cartoons, for example, can powerfully depict points of views by the manner in which they portray the persons, places, things, or other matters.

Lawyers should also remember that the iconic signification can be all the more powerful or memorable by focusing on unexpected points of resemblance. For example, Oscar Wilde famously refers to a person with a "shrill horrid voice" as "a peacock in everything but beauty." 87

In addition to their imitative aspects, icons interrelate with the nonimitative in ways that lawyers should also understand if they are to effectively use and respond to iconic signifiers.

\section{Functions of Background}

As Schapiro points out, icons such as images or paintings generally appear against the background, a background which we often assume today to be rectangular and having a "clearly defined smooth surface on which one draws and writes." 88 Of course, such a background is not compelled, and lawyers seeking the most effective form of, for example, iconic exhibits should consider whether other background shapes and textures would be preferable in the lawyers' specific situation. ${ }^{89} \mathrm{We}$ can go even further and ask whether we want a clear distinction between background and image. In this regard, Schapiro reminds us that "prehistoric wall paintings and reliefs ... had to compete with the

86. One can, of course, untether photographs by "touching them up" or by otherwise altering them. However, to the extent this breaks the "real" relation with the matters depicted, the photographs by definition no longer remain indexical. They would, of course, remain iconic to the extent of any resemblance to the signified.

87. OSCAR WILDE, THE PICTURE OF DORIAN GRAY 190 (Michael Patrick Gillespie ed., 2007) (1890). Jakobson gives us another striking example: "A missionary blamed his African flock for walking [around] undressed. 'And what about yourself?' they pointed to his visage, 'are not you, too, somewhere naked?' 'Well, but that is my face. 'Yet in us,' retorted the natives, 'everywhere it is face." Roman Jakobson, Closing Statement: Linguistics and Poetics, in SEMIOTICS: AN INTRODUCTORY ANTHOLOGY 145, 173 (Robert E. Innis ed., 1985).

88. Meyer Schapiro, On Some Problems in the Semiotics of the Visual Arts: Field and Vehicle in Image-Signs, in SEMIOTICS: AN INTRODUCTORY ANTHOLOGY 206, 209 (Robert E. Innis ed., 1985).

89. Thus, Schapiro tells us of those who "have painted on pebbles and on found fragments of natural and artificial objects, exploiting the irregularities of the ground and in the physiognomy of the object as part of the charm of the whole." Id. at 211. Schapiro also reminds us that ancient cave paintings were on "the rough wall of a cave" where "the irregularities of earth and rock show through the image," and the painter worked "on a field with no set boundaries and thought so little of the surface as a distinct ground that he often painted his animal figure over a previously painted image without erasing the latter, as if it were invisible to the viewer." Id. at 209. 
noise-like accidents and irregularities of a ground which was no less articulated than the sign and could intrude upon it." 90

\section{Functions of Physical Frames}

As Schapiro also points out, iconic images may or may not have physical frames. ${ }^{91}$ Leaving the image unframed may make it appear "more completely and modestly the artist's work."92 Depending on the choice of frame, the frame can help accent the iconic image, can serve as a "finding and focusing device," and can act "like a window frame through which is seen a space behind the glass" where the world of the iconic image lies. ${ }^{93}$

\section{Functions of Size}

Additionally, size plays a role in how we perceive the iconic image. Our reaction may change as a function of "the size of the field and the size of different components of the image relative to real objects which they signify and relative to each other." ${ }^{4}$ For example, one might paint Alexander the Great as larger than his soldiers to reflect the notion of "Alexander as the Great." 95

\section{Functions of Place}

Where we have a bounded visual field, iconic images can change in quality depending upon their location within various parts of the field, such as "upper and lower, left and right, central and peripheral, the corners and the rest of the space."96 For example, a figure off-center can appear "anomalous, displaced, even spiritually strained."97 All of these non-imitative aspects of iconic images can thus play important roles in lawyers' use of, and response to, iconic signifiers.

\section{Icons, Art, and Knowledge}

In any case, the semiotic possibilities of the icon discussed above should persuade lawyers of the value and importance of icons. Hopefully this includes lawyers who previously may have dismissed icons' importance because of a more general belief that art is merely "some al-

90. Id

91. Id. at $212-13$.

92. Id.

93. Id. at 212 .

94. Id. at 219 .

95. Id. at 221.

96. Id. at 214 .

97. Id. 
ien universe into which we are magically transported for a time." $98 \mathrm{Be}-$ cause icons signify, we lawyers, too, can say that art can be "knowledge," and in such a case, "experiencing an artwork means sharing in that knowledge." ${ }^{99}$ I will return to icons in Part IV below, when I discuss the power of mixing icons, indices, and symbols.

\section{Symbols}

\section{Correlation of Convention or Stipulation}

Taking inspiration again from Peirce, symbols are signs whose signifier and signified are correlated solely 100 by convention or by habit, 101 or otherwise "by the fact that [they are] used and understood as such." 102 Symbols would thus include "words, sentences, books, and other conventional signs." 103 Chandler again usefully expands upon Peirce by noting that the symbolic mode is "a mode in which the signifier does not resemble the signified but which is fundamentally arbitrary or purely conventional - so that this relationship must be agreed upon and learned." 104 Chandler would thus expand upon the above list of symbols to include, for example, "language in general (plus specific languages, alphabetical letters, punctuation marks, words, phrases and sentences), numbers, morse [sic] code, traffic lights, [and] national flags." 105

\section{Symbolic Signifiers: Freedom yet Restraint}

Any "concrete object," "abstract entity," "idea or "thought," perceptible [object]," "physical event," or "imaginable [object]"106 might serve as a symbolic signifier either by convention or by stipulation. ${ }^{107}$ If it is convenient, for example, for parties in a debate to use a white stone to refer to one proposition and a gray stone to refer to another, there is no semiotic reason why the parties cannot so stipulate. This potential flexibility thus presents lawyers with vast potential options

98. HANS-GEORG GADAMER, TRUTH \& METHOD 83 (Joel Weinsheimar \& Donald G. Marshall trans., rev. ed. 2004).

99. Id. at 84 .

100. See $1 \& 2$ PEIRCE, supra note 7 , at 2.299 ("The symbol is connected with its object by virtue of the idea of the symbol-using mind, without which no such connection would exist.").

101. See id. at 2.292, 2.297.

102. See id. at 2.307.

103. Id. at 2.292.

104. CHANDLER, supra note 44, at 36.

105. Id.

106. See NÖTH, supra note 8 , at 80 ; see also $1 \& 2$ PEIRCE, supra note 7 , at 2.230 (failing to parse between "sign" and "signifier" in discussing the "perceptible" and the "imaginable").

107. To the extent any such symbols indicate a speaker's meaning by being in a causal or other real connection with such meaning, we could also speak of such symbols of indices of such meaning. See supra section III.A on indices. 
That said, however, such theoretical freedom can face much realworld pushback. Unconventional signifier usage, for example, that violates linguistic community norms or that otherwise fails to move audiences in ways desired will, on its face, fall flat. Lawyers must remember that their surrounding linguistic communities require justification when signifier usage deviates from norms. ${ }^{108}$

Such potential flexibility of symbolic signifiers can also raise other potential legal issues. For example, since any "concrete object," "abstract entity," "idea or "thought," "perceptible" object, "physical event," or "imaginable" object ${ }^{109}$ can potentially serve as a symbolic signifier, can everything potentially become protected speech or expression under the First Amendment to the extent one claims signifier usage in such a case? Obviously, there must be limits here (for example, no reasonable person would find the First Amendment protects tossing live grenades as signifiers of political dissatisfaction), and I briefly touch on semiotics and the First Amendment in Part VIII.

\section{Correlation and the Transubstantiation Fallacy}

When exploring the correlation of signifier and signified, lawyers must take care themselves (as well as help their clients to take such care where appropriate) not to confuse a signifier with its signified. Such confusion, which one might call the "transubstantiation fallacy," can cause much unnecessary confusion and angst.

For example, the flag for many signifies one's country. However, the flag itself, of course, is not one's country. Thus, trampling the flag is not trampling one's country or otherwise physically harming one's country (though such action may signify extreme disrespect for one's country). When addressing such impassioned subjects ${ }^{110}$ as protests involving damage to national flags, rational discourse thus focuses on flags as signifiers rather than as nations transubstantiated. Similarly, burning a picture of a beloved person to send a message about that person is not equivalent to burning that person, and, again, rational discourse should focus on burning photos as signifiers rather than as persons transubstantiated. In a different manifestation of the transubstantiation fallacy, using icons as signifiers of divine or religious figures is not idolatry in the sense of equating such iconic signifiers with the divine or religious figures signified. Had Cromwell, for example, grasped the transubstantiation fallacy, perhaps much treasured Brit-

108. See Lloyd, supra note 27, at 227-28.

109. See NÖTH supra note 8.

110. Transubstantiation beliefs seem especially likely to occur when dealing with signifieds of high regard. Thus, for example, we have the transubstantiation debate regarding Christian Communion. See Michael Newsom, PanProtestantism and Proselytizing: Minority Religions in a Protestant Empire, 15 WIDENER L. REV. 1, 12-33 (2009). 
ish iconography would have escaped his destruction. ${ }^{111}$ In any case, awareness of the transubstantiation fallacy should expose the confused "anti-idolatrous" iconoclast "who destroys religious images"112 used as icons to signify what they resemble.

\section{E. Beyond Correlation: Other Classification Possibilities}

Having now finished an overview of sign classifications based upon three possible correlations of the signifier to the signified (the indexical, iconic, and symbolic), I briefly note (without exhaustive classification) that we can classify signs in other ways. For example, we can classify signs based on the qualities of their signifiers. ${ }^{113}$ Using a contemporary definition of quality as "an inherent feature: PROPERTY" which includes "an effect that an object has on another object or on the senses," 114 we can thus distinguish and choose signifiers on this basis as well. Hence, a lawyer might consider whether a red or some other color font used in a juror exhibit might more powerfully convey certain information than a traditional black font. She might consider whether a color photograph serves better than a black-and-white photograph (or vice versa). In fact, qualities of either sort of photograph may miss useful qualities that could be found in a sound recording. If so, is it better to supplement the photographs with sound? Or might it be better to synchronously fuse certain qualities of sight and sound by using a film juxtaposing such qualities? Qualities of signifiers can thus play critical roles whether such signifiers are indexical, iconic, or symbolic. 115 Lawyers can also classify and consider signs by the types of their signifieds including such familiar signifieds to lawyers as terms, propositions, and arguments. ${ }^{116}$ Although lawyers are often first disposed to focusing on terms, propositions, and arguments in themselves, they can benefit by considering whether other approaches might be more effective, such as using terms propositions, and arguments in narrative or dialogue. ${ }^{117}$

111. ANTONIA FRASER, CROMWELL: THE LORD PROTECTOR 102-04 (1973).

112. See Iconoclast, MERRIAM-WEBSTER'S NEW COLLEGIATE DICTIONARY (9th ed. 1983).

113. See, e.g., 1 \& 2 PEIRCE, supra note 7 , at 2.243-2.244; 2.254. Using further distinctions, Peirce surveys ten classes, see id. at 2.264 (diagramming such ten classes), which he further expands. See 8 PEIRCE, supra note 18, at 8.343-76.

114. See Quality MERRIAM-WEBSTER's COLLEGIATE DiCTIONARY (9th ed. 1983); Property, MERRIAM-WEBSTER'S NEW COLLEGIATE DICTIONARY (9th ed. 1983); see also 1 \& 2 PEIRCE, supra note 7, at 2.244, 2.2374, 2.375, 2.376, 2.377 .

115. Again, I rely on the contemporary definition of "quality" noted in the text. Those interested in Peirce should note his claim that "[s]ince a quality is whatever it is positively in itself, a quality can only denote an object by virtue of some common ingredient or similarity" and thus works iconically. See $1 \&$ 2 PEIRCE, supra note 7 , at 2.254 .

116. See id. at 2.261, 2.262, 2.263.

117. For example, Peirce notes that "our own thinking is carried on as a dia- 


\section{INDICES, ICONS, SyMBOLS, AND EXPANSIVE LEGAL RHETORIC}

\section{A. Lawyers and the Semiotics of Rhetoric: More than Just Words}

As the above discussion of the various types of signs, signifiers, and the signified should now make clear, legal rhetoric should hardly be confined to words alone, and a lawyer's toolbox containing only words is much impoverished. Words are only one type of symbol, and one may also use other types of symbols not only to enrich one's meaning, but to capture meaning that words alone might not capture. For example, the phrase "love of country" might be bolstered by the display of that country's flag. Additionally, as we have seen, symbols do not exhaust the types of signs available to lawyers and others. Lawyers and others can also enrich and even expand their meaning by use of icons and indices as well. Facility with all types of signs thus not only enriches expression, but allows expression of meaning that might escape use of words alone. Thus, again, words are a critical part of a lawyer's toolbox but so are the other types of signs. In the next section, I turn to a bit of Shakespeare to underscore the importance of an expansive semiotics.

\section{B. Lawyers and the Semiotics of Rhetoric: Antony's Funeral Oration}

Once lawyers have a good grasp of how signs work and how signs may be classified by correlations of the signifier and the signified (in addition to other methods of classification noted in section III.E), lawyers can find much semiotic instruction in Shakespeare's rendition of Antony's funeral oration for Caesar. ${ }^{118}$ They can see quite well how words alone ignore much of the semiotic arsenal available to them. Though Antony's entire speech bears reading again and again, space limitations require that I touch on select passages in the sequence in which they appear in Shakespeare. Had I more space, I would also explore other classics of expansive semiotics such as (1) the illustrated writings of William Blake, which demonstrate an unparalleled blending of the iconic and the nonverbal symbolic with the verbal symbolic; and (2) Barthes' exploration of the power of intermingling icons, symbols, colors, placement against the background field, and more in his examination of a Panzani advertisement. ${ }^{119}$ I would suggest a careful

logue" which of course is "subject to almost every imperfection of language." 5 \& 6 PEIRCE, supra note 6, at 5.506.

118. See generally WILLIAM SHAKESPEARE, THE TRAGEDY OF JULIUS CAESAR act 3, sc. 2 (Albert Harris Tolman ed., World Book Company 1913) (1599). In addition to the selections examined here, I have examined more of Antony's speech elsewhere. See generally Harold A. Lloyd, Let's Skill All the Lawyers: Shakespearean Lessons in Law and Rhetoric, 6 ACTA IURIDICA OLOMUCENSIA 9, 49-55 (2011).

119. See Roland Barthes, Rhetoric of the Image, in SEMIOTICS: AN INTRODUCTORY ANTHOLOGY 190, 192-205 (Robert E.' Innis ed., 1985); The William Blake Archive, http:// www.blakearchive.org/ [https://perma.cc/QV7H-3WAT]. I hope to do a separate article on William 
review of Blake's illustrated works and Barthes' article for lawyers seeking to improve their rhetoric by grasping the power of a semiotics beyond words alone.

Although we have only the words from the oration, as we will see, the words make plain that the oration turns on much more than mere words. For example, we can begin our selections with the following lines that powerfully rely on icons and indices as well as words:

"My heart is in the coffin there with Caesar,

And I must pause til it come back to me." 120

Here Antony indexically points to Caesar's body which is both an index of his murder (being physically connected to his murder) and an icon of Caesar (by virtue of resemblance). The metaphor of Antony's heart briefly sharing Caesar's coffin also helps paint a powerful picture, a powerful icon of grief.

As with use of Caesar's body as a signifier above, Antony continues demonstrating adeptness at using the same signifiers for multiple functions. He invokes Caesar's will as both an index and symbol of Caesar's love of the Roman people. It is an index to the extent it is directly related to and flowing from Caesar's affection. It is a symbol to the extent it stands for Caesar's love. Antony also mixes in other signifiers: the "sacred blood" as index of the crime and both index and symbol of the "sacred" man, and hair as both index and symbol of the man. Thus, Antony speaks in a suspense-building way by calling attention to the will and first feigning not to read it:

But here's a parchment with the seal of Caesar;

I found it in his closet; 'tis his will:

Let but the commons hear this testament-

Which, pardon me, I do not mean to read-

And they would go and kiss dead Caesar's wounds,

And dip their napkins in his sacred blood,

Yea, beg a hair of him for memory .... ${ }^{121}$

Antony also knows the power of centering icons in the field of vision. To accomplish this with the corpse's iconic power of resemblance to the once living man, Antony thus continues:

You will compel me, then, to read the will?

Then make a ring about the corpse of Caesar, And let me show you him that made the will.

Shall I descend? and will you give me leave?122

Blake's lessons for lawyers including Blake's semiotic insights.

120. SHAKESPEARE, supra note 118, at act 3, sc. 2, lines 105-06.

121. Id. at act 3, sc. 2 , lines $127-33$.

122. Id. at act 3, sc. 2, lines 155-58; see supra section III.B.5 above on icons and place. 
With the remnants of Caesar and his bloody clothes centered and in closer focus, Antony continues mixing his various signs as he examines the body and bloody clothes:

Look, in this place ran Cassius' dagger through:

See what a rent the envious Casca made:

Through this the well-beloved Brutus stabb'd;

And as he pluck'd his cursed steel away,

Mark how the blood of Caesar follow'd it,

As rushing out of doors, to be resolv'd

If Brutus so unkindly knock'd or no:

For Brutus, as you know, was Caesar's angel:

Judge, O you gods, how dearly Caesar lov'd him!

This was the most unkindest cut of all. . . ${ }^{123}$

In addition to pointing out the indexical evidence of specific conspirators having participated in the crime, Antony here also uses the icon of metaphor when he speaks of blood that "followed" the stabs of Brutus to determine whether Brutus had in fact "so unkindly knock'd."

Noting that Caesar fell "at the base of Pompey's statue," 124 Antony continues:

O, what a fall was there, my countrymen!

Then I, and you, and all of us fell down,

Whilst bloody treason flourish'd over us.

$\mathrm{O}$, now you weep, and I perceive you feel

The dint of pity: these are gracious drops.

Kind souls, what! weep you when you but behold

Our Caesar's vesture wounded? Look you here,

Here is himself, marr'd, as you see, with traitors. ${ }^{125}$

Here with Caesar's fall, Antony uses an event as a signifier that he extends metaphorically (and thus iconically) to the resulting fall of Antony and the crowd ("all of us fell down"). And, of course, once again Antony points to Caesar's "marr'd" body as indicating murder.

Powerfully showing further that indices can be compounded as iconic metaphors, Antony continues:

I tell you that which you yourselves do know;

Show you sweet Caesar's wounds, poor, poor dumb mouths, ${ }^{126}$

And bid them speak for me: but, were I Brutus, And Brutus Antony, there were an Antony

Would ruffle up your spirits, and put a tongue

123. SHAKESPEARE, supra note 118 , at act 3 , sc. 2 , lines $172-81$.

124. Id. at act 3 , sc. 2 , line 186.

125. Id. at act 3 , sc. 2 , lines $188-95$.

126. Antony turns this powerful metaphor into allegory by repeated use in what follows. See RICHARD A. LANHAM, A HANDLIST OF RHETORICAL TERMS 4-6 (2d ed. 1991). 
In every wound of Caesar that should move

The stones of Rome to rise and mutiny. ${ }^{127}$

The wounds again serve here as indices of the murder, but now they are also iconically "poor dumb mouths" waiting for their tongues to call out mutiny. This extraordinary metaphor shows that Antony (like good lawyers) fully appreciates the power of image over argument in appropriate circumstances.

Antony returns to the will to make multiple indexical points. The now-disclosed contents of the will indicate Caesar's goodness and love for the Roman people. "Caesar's seal" indicates the authenticity of the will. Thus, Antony continues:

Here is the will, and under Caesar's seal:

To every Roman citizen he gives,

To every several man, seventy-five drachmas. . . .

Moreover, he hath left you all his walks,

His private arbors, and new-planted orchards,

On this side Tiber. He hath left them you,

And to your heirs forever-common pleasures

To walk abroad and recreate yourselves.

Here was a Caesar. When comes such another? ${ }^{128}$

When he realizes that his mixture of symbols, indices, and icons has proven powerfully effective, Antony remarks:

Now let it work. Mischief, thou art afoot;

Take thou what course thou wilt. ${ }^{129}$

Hopefully the selective remarks above demonstrate why lawyers should ponder the entire speech and its semiotics. Hopefully such selective remarks also demonstrate how lawyers who rely primarily on words rely on a much-impoverished semiotics.

\section{Semiotics AND SPeEch ACts of InTEREST to LAWYeRS}

Having seen how Antony orchestrates a panoply of sense with different types of signs and different types of expression, we can now note in more detail how lawyers encounter multiple types of speech acts (i.e., acts performed with signs) ${ }^{130}$ in their practice. Although I shall use the

127. SHAKESPEARE, supra note 118 , act 3, sc. 2, lines 221-27.

128. Id. at act 3 , sc. 2 , lines $254-56,261-66$.

129. Id. at act 3 , sc. 2 , lines $275-76$.

130. My semiotic definition is broader than definitions focusing only on words. See, e.g., Speech Acts, OXFORD DICTIONARY OF PHILOSOPHY (3d ed. 2016) (defining speech acts as "acts performed when words are uttered"). In discussing speech acts, J.L. Austin used the following distinctions: (1) Locutionary acts consist of "the phonetic act, of making noises, the phatic act of making a grammatical sentence, and the rhetic act of saying something meaningful." Id. (2) Illocutionary acts are "what is done in saying something, such as threatening or praying or promising." Id. (3) Perlocutionary acts are 
term "speech act" because of its wide usage, "semiotic act" would be more accurate and useful since words are only one type of signs, and I would encourage such change of terminology.

\section{A. Assertives, Directives, Commissives, Expressives, Declaratives, Verdictives}

Although I do not claim that these are the only or definitive categories of speech acts, Alan Cruse lists several categories which are useful for the purposes of this Article. ${ }^{131}$

"Assertives" are speech acts that "commit the speaker to the truth of the expressed proposition," such as speech acts which "state, suggest, boast" or "claim" or "report." 132 Stating "X has been banned for ninety days," is thus an example of an assertive speech act. "Directives" are speech acts having "the intention of eliciting some sort of action on the part of the hearer," such as giving an "order" or "command." 133 An order of a public official that commands the banning of $\mathrm{X}$ for ninety days would be an example of such a directive speech act by directing, for example, a group of persons not to use X. "Commissives" are speech acts that "commit the speaker to some future action" such as promising, offering, contracting, or threatening. ${ }^{134}$ "Expressives" are speech acts which "make known the speaker's psychological attitude to a presupposed state of affairs," such as praising, blaming, thanking, and congratulating. ${ }^{135}$ Blaming X for causing certain ills would be an example of such an expressive speech act. "Declaratives" are speech acts which "bring about a change in reality" which is "over and above the fact that they have been carried out." 136 For example, the declaratives "I hereby resign as President" or "I hereby open this exhibition" make actual changes in the social fabric of the world beyond just adding those uttered phrases to the set of phrases uttered in this world.137 Such declaratives change who is President (in the former) and open up an exhibition (in the latter). Thus, in the case of resignation, the declarant would "no longer hold the post [the declarant] originally held, with all that entails." 138 Additionally, J.L. Austin speaks of a group of speech

the "effects on hearers, such as frightening them." Id.

131. Alan CRUSE, MEANING IN LANGUAGE: AN INTRODUCTION TO SEMANTICS AND PRAGMATICS 374-75 (2d ed. 2004). For other earlier and "classic" overviews of speech acts, see generally J. L. AUSTIN, HOW TO DO THINGS WITH WoRDS (J. O. Urmson \& Marina Sbisà eds., Harv. Univ. Press 2d ed. 1975); SEARLE, supra note 13, at 166.

132. CRUSE, supra note 131, at 374.

133. Id. at $374-75$.

134. Id. at 375 .

135. Id.

136. Id. See also SEARLE, supra note 13, at 166 (recognizing "declarations, where we bring about changes in the world with our utterances").

137. See CRUSE, supra note 131, at 375 .

138. Id. at 343 . 
acts called "verdictives" that are such "judicial acts" as convicting, acquitting, and fact finding. 139

\section{B. Other Possible Speech Act Distinctions}

For purposes of this Article, I draw from the speech act categories set forth above, although I acknowledge reasonable minds can differ as to how to draw performative categories (just as reasonable minds can differ about many other categories that we draw). One might argue, for example, that verdictives are in fact blends of assertives to the extent that they assert fault, directives to the extent that they direct a defendant to pay money, expressives to the extent that they blame a defendant, and declaratives to the extent that they change someone's legal status through sentencing. However, speaking of the "verdictive" is useful and timesaving for the brief jury exploration I do below in Part VI. Such categories are also otherwise useful in the discussion of sense and meaning more broadly signified by various types of signs.

\section{INTERPRETATION AND CONSTRUCTION OF SPEECH ACTS AND SIGNS}

Lawyers, of course, can be faced with all such types of speech or semiotic acts. In doing so, they can face such questions as who should count as the speaker/writer, who should count as the hearer/reader, and whose meaning should control. I therefore explore these fundamental semiotic issues.

\section{A. Utterer/Speaker/Author versus Hearer/Reader Meaning}

Starting first with whose meaning should control, we must remember that to have meaning, we must have interpretation. Again, Charles Sanders Peirce tells us that "nothing is a sign unless it is interpreted as a sign," 140 and Eco tells us that a "sign is not only something which stands for something else; it is also something that can and must be interpreted." 141

Of course, utterer/author/speaker and reader/hearer meaning can differ, and this leads us to the question of whose (if anyone's) meaning should prevail. As a fascinating example of such difference, Robert Benson tells us that the author's meaning for The Wizard of $\mathrm{Oz}$ is very different from the way most readers understand the work today. ${ }^{142} \mathrm{Ac}$ cording to Benson, rather than a fairy tale of good and evil involving a

139. AUSTIN, supra note 131, at 153.

140. 1 \& 2 PEIRCE, supra note 7 , at 2.306 .

141. ECO, supra note 9, at 46.

142. ROBERT BENSON, THE INTERPRETATION GAME: HOW JUdGES AND LAWYERS MAKE THE LAW 52-53 (2008). 
girl coming of age, the author meant the work to be a populist, political allegory. ${ }^{143}$

An abbreviated list of the author's meanings claimed by Benson include: Dorothy as representing the average person, the Yellow Brick Road as representing the gold standard, Dorothy's silver (as opposed to the film's red) slippers as representing free silver money, $\mathrm{Oz}$ as an abbreviation of "ounce" (used to measure gold and silver), the Wicked Witch of the East as representing capitalists and bankers, the Tin Man as representing the factory worker, the Scarecrow as representing the farmer, the Munchkins as representing the "little people," the Cowardly Lion as representing William Jennings Bryan, and the Wizard as representing the President who governs the realm by his sleight of hand. ${ }^{144}$ The typical modern reader, having little or no awareness of such allegory from another time, of course, will read the work quite differently.

The law is aware that author/speaker meaning can differ from reader/listener meaning. Thus, the Supreme Court has noted, in Spence $v$. Washington, that "[a] person gets from a symbol the meaning he puts into it, and what is one man's comfort and inspiration is another's jest and scorn." 145 That said, however, we still have the question of whose (if anyone's) meaning should prevail when meanings conflict.

\section{B. Whose Meaning Controls: Some Initial Definitions and Distinctions}

Focusing on determining whether author/speaker or reader/ hearer meaning should control in several types of nonfiction ${ }^{146}$ speech acts of

143. Id. at 52 .

144. Id

145. Spence v. Washington, 418 U.S. 405, 413 (1974) (quoting W. Va. Bd. of Educ. v. Barnette, 319 U.S. 624, 632-33 (1943) (internal quotations omitted)). 146. I acknowledge that the default toward speaker meaning discussed below cannot consistently work across the realm of fiction. Even if one focuses on author meaning in fiction, an author of a particular work of fiction can of course mean for readers to embrace reader meaning of the work. The author of a great poem, for example, can entice readers to become enmeshed in their own meanings that transcend and even contradict the author's. A nonfiction speaker, however, who claims that the child he holds in his arms is "his son" would not by that statement invite hearers to contradict his meaning. I will not otherwise address fictional meaning in this Article. However, for those wishing to explore whether interpretation of fiction might shed light on legal interpretation, Kent Greenawalt provides an interesting discussion which ultimately concludes that "the differences between literary and legal interpretation are so great that an understanding of the first will tell us almost nothing about how the debatable practical issues concerning legal interpretation should be treated." KENT GREENAWALT, REALMS OF LEGAL TNTERPRETATION: CORE ELEMENTS AND CRITICAL VARIATIONS 137 (2018). That said, Prof. Greenawalt does note, as would I, that "novels and poems, as well as biographies and autobiographies, can teach us about human beings and our societies" and can thus have "practical significance" for the law. Id. at 135-36. I would go further and raise this claim to "great practical significance" for the law. See also Lloyd, supra note 45, at 132-36, for the importance of the humanities in law and legal education. 
particular interest to lawyers, I must next explore some critical distinctions that come into play in determining such operative meaning.

\section{Interpretation versus Construction}

First, we should note the critical distinction between interpretation and construction. Interpretation determines "the linguistic understanding of the provisions at issue," 147 whereas construction determines the "legal meaning" of a text. ${ }^{148}$ A text's "legal meaning" includes "the authoritative meaning given to it by a judge," whereas the "linguistic meaning" is "the meaning communicated by the language of the text in light of the appropriate context of the communication." 149 For example, one can imagine two parties carefully addressing all the terms of a lease agreement for a term of four years and video recording their careful reciting of all such terms. Interpretation would involve discerning the linguistic meaning of such provisions. Construction would involve determining the legal effect of such a video-recorded agreement. If, for example, the applicable jurisdiction required leases of more than three years to be in writing, then one must construe the lease as unenforceable even though the linguistic terms might be easily interpreted.

\section{Actual versus Hypothetical Speaker Meaning}

Second, by "speaker," one will find in the literature not only references to actual speakers in question but also to such notions as "a normal speaker of English, using [words] in the circumstances in which they were used"150 and "the reasonable maker of statements." 151

Since hypothetical speakers by definition do not exist, they cannot, without more, provide the actual mind required to interpret or generate speaker meaning. ${ }^{152}$ To resolve this semiotic difficulty, we must de-

147. Brian G. Slocum, Introduction, in THE NATURE OF LEGAL INTERPRETATION: WHAT JURISTS CAN LEARN ABOUT LEGAL INTERPRETATION FROM LINGUISTICS AND PHILOSOPHY 1, 5 (Brian G. Slocum ed., 2017) [hereinafter Slocum, Introduction].

148. See id.; Brian G. Slocum, The Contribution of Linguistics to Legal Interpretation, in THE NATURE OF LEGAL INTERPRETATION: WHAT JURISTS CAN LEARN ABOUT LEGAL INTERPRETATION FROM LINGUISTICS AND PHILOSOPHY 14, 16 (Brian G. Slocum ed., 2017) [hereinafter Slocum, Contribution of Linguistics].

149. Slocum, Contribution of Linguistics, supra note 148, at 16.

150. Karen Petroski, The Strange Fate of Holmes's Normal Speaker of English, in THE NATURE OF LEGAL INTERPRETATION: WHAT JURISTS CAN LEARN ABOUT LEGAL INTERPRETATION FROM LINGUISTICS AND PHILOSOPHY 105, 107

(Brian G. Slocum ed., 2017) (quoting Holmes).

151. Id. at 113 (referring to Justice Thomas).

152. See supra section VI.A. 
rive the meaning from a real speaker or reader who can convey the necessary intentionality. ${ }^{153}$

For example, in reading a particular judicial opinion that finds that a "reasonable maker of statements" would "intend" X, we might derive the hypothetical speaker's intent from the judge who writes the opinion. We might say that she interprets the signifiers in ways that she believes such a hypothetical speaker would do. We might, on the other hand, attempt to derive the meaning from other actual speakers such as the majority of speakers of English, and may even sample actual speakers to such an end. However, whomever we choose as the existing speaker or speakers to provide such derivative meaning (the "source speakers"), the point is to remember that such meaning is in fact derived, and that such meaning does not come from non-existent, hypothetical speakers who by definition cannot provide the actual intentionality required for meaning.

Although hypothetical speakers of course do not exist, the source speakers and their meaning can be an object of inquiry in the realm of public, nonfictional experience. Thus, as discussed in section VI.D.4.b below, legislators and their meanings can be such objects of inquiry where we derive legislative meaning from such legislators in the manner discussed in such section IV.D.4.b below.

\section{Actual versus Hypothetical Reader Meaning}

Third, turning to readers, we can find distinctions in the literature between types of actual readers (such as between "ordinary readers" and "extremely well informed" readers). ${ }^{154}$ We can also see references to hypothetical readers of various characteristics, including those having the ability to "perceive relevant factors that are beyond the capacities of the vast majority of human readers."155 Thus, Justice Scalia would use for legislation a "reasonable reader," an "objectivizing construct," "who is aware of all the elements (such as the canons) bearing on the meaning of the text, and whose judgment regarding their effects is invariably sound. Never mind that no such person exists." 156 I refer the reader to section VI.B.2 above regarding the role of, and concerns with, the derivative meaning required for hypothetical persons.

Preferring greater adherence to reality, the interpretation principle I propose in section VI.C below will use instead, for example, the mean-

153. See SEARLE, supra note 13, at 27-29 (on derived intentionality); see also supra section I.B.

154. Kent Greenawalt, Philosophy of Language, Linguistics, and Possible Lessons about Originalism, in THE NATURE OF LEGAL INTERPRETATION: WHAT JURISTS CAN LEARN ABBOUT LEGAL INTERPRETATION FROM LINGUISTICS AND PHILOSOPHY 46, 56-57 (Brian G. Slocum ed., 2017).

155. Id. at 57.

156. SCALIA \& GARNER, supra note 1 , at 393. 
ings used by actual legislators debating and voting on legislation where reasonable evidence exists as to such actual legislators' meanings.

\section{Controlling Meaning versus Controlling Signifiers}

Finally, as we examine whose meaning controls, we should not confuse questions of the signified with questions of appropriate signifier use. As a matter of pure semiotics, we have seen that signifiers can include, for example, potentially any "concrete object," "abstract entity," "idea or "thought," "perceptible object," "physical event," or "imaginable object." 157

We must remember, however, that seeking an actual speaker's meaning conveyed by any such particular signifier is a separate inquiry from examining the legality of the use of such a signifier. For example: trademark law protects a "word, phrase, logo, or other graphic symbol used by a manufacturer or seller to distinguish its product or products from those of others"; 158 copyright law protects "an original work of authorship (such as a literary, musical, artistic, photographic, or film work) fixed in any tangible medium of expression"; 159 and criminal law would not permit killing a public official as a signifier of political protest.

Given such restrictions, a vendor's intent, for example, that a certain mark refer only to the vendor's products of course does not grant the vendor rights to use that mark if others have trademark protection for use of the mark. Although we may be able to determine, as a matter of interpretation, that such a vendor meant the mark only to refer to the vendor's products (the vendor's intended signified), trademark law can refuse him use of such a signifier and thereby provide remedies to the lawful holder of the mark. I further explore restrictions on signifier usage in --Part VIII below.

\section{Whose Meaning of Signs Controls}

In light of the foregoing, when determining whose meaning of signs controls, I propose the following principle of interpretation as the default starting position for nonfiction speech (or semiotic) acts.

\section{The Principle of Speaker Meaning}

Under the "Principle of Speaker Meaning," the actual speaker's meaning as it unfolds over time controls as a matter of interpretation

157. NÖTH, supra note 8, at 80; see also 1 \& 2 PEIRCE, supra note 7 , at 2.230 .

158. Trademark, BLACK's LAW DICTIONARY (7th ed. 1999) (noting that "[i]n effect, the trademark is the commercial substitute for one's signature").

159. Copyright, BLACK'S LAW DICTIONARY (7th ed. 1999). 
where such speaker's meaning is reasonably discernible, even though the evidence may be sparse, conflicting, or otherwise complex. One must thus attempt to make a reasonable determination of such meaning in light of the available evidence, however sparse, conflicting, or otherwise complex. Under the Principle of Speaker Meaning, such evidence includes all available intrinsic and extrinsic evidence that may shed light on the speaker's meaning including, without limitation: the applicable speaker's (1) cognitive contexts; (2) physical and temporal contexts; (3) social, cultural, and human contexts; (4) discourse contexts; (5) textual or internal contexts; and (6) other relevant contexts. ${ }^{160}$

For example, we might determine a speaker's meaning of "eye" in the phrase "the evil eye" as meaning the "eye of a hurricane" (rather than the eye of a person that can inflict harm) by looking at such available contexts. We might thus look at: the notion of the hurricane then concerning the speaker (the cognitive context); the speaker's physical and temporal connection to the approaching hurricane (the physical and temporal contexts); the speaker's expressed concern with others about the community damage of a direct hit by the hurricane (the social, cultural, and human context as well as the discourse context); and earlier references in the speaker's text to the hurricane (the textual or internal context). Such contexts might thus reasonably evince a meaning of a hurricane eye rather than a human eye that can inflict harm.

\section{Rationales for the Principle of Speaker Meaning}

I propose this Principle of Speaker Meaning for multiple reasons. First, we cannot, without patent falsehood, claim that a speaker's reasonably discernible linguistic meaning is instead the linguistic meaning of another person or entity unless, of course, the speaker intends to incorporate others' linguistic meanings. ${ }^{161}$ Second, if we fundamentally respect the right of speakers to speak for themselves (and thus to be accountable for their meaning and not for the meaning of others they do not embrace), we cannot, as a matter of interpretation, respect such right yet substitute the meaning of another (whether actual or hypothetical) for such speakers' reasonably discernable linguistic meaning. Third, as we shall also see in section VI.C.4.b, construction is better in-

160. See Lloyd, supra note 5, at 254-63. As discussed in note 218 infra, in the case of legislation, cognitive and discourse context includes legislative history. To the extent applicable law would limit the relevant intrinsic or extrinsic evidence that might be considered as a matter of interpretation, the Principle of Speaker Meaning would counsel change.

161. As noted in section VI.C.5 infra, a person can, for example, incorporate into a document the meaning of others, as when one incorporates, without change, a particular concept of another. As also noted in Section VI.D.4.b.iv infra, legislators who do not read a bill can incorporate or adopt the meaning of committee members or others who have advanced a bill. 
formed when it considers prior searches for actual speaker meaning. Thus, Greenawalt correctly claims that "[a]ny plausible argument for disregard of intentions must rest on claimed specific obstacles, not ordinary understandings."162

\section{Evidence and the Applicable Standard of Proof}

\section{a. Varying Complexities of Evidence}

In discerning actual speaker meaning, the available intrinsic and extrinsic evidence may be straightforward, conflicting, otherwise complex, or nonexistent beyond any words that might have been used. We must nonetheless attempt to do our best. For example, a speaker may say "X" yet claim that such statement was meant ironically, or a speaker may both say "X" and "not X." In such cases, we must weigh all the evidence to attempt to find whether the first speaker was indeed speaking ironically and whether the second speaker truly contradicted herself. After reviewing all the evidence, we might find that the speaker's expression of "not X" was a slip of the tongue and she therefore indeed meant "X," and that the first speaker truly spoke ironically.

Even where mixed evidence does not result from slips of the tongue or other error, grappling with mixed or inconsistent meanings can result in usable linguistic meaning. To take an academic example, a quantum theorist can usefully help scientists by exploring and speaking about light in mixed or contradictory ways as both a particle and a wave. Additionally, a theologian can help believers by exploring and speaking about how Christ is both God and man. The Principle of Speaker Meaning would take such linguistic meaning in its contradictory senses in the contexts and for the purposes used. ${ }^{163}$

Of course, speaker meaning may not be reasonably discernible in certain cases. In those cases, we will have no choice but to turn to construction (as enlightened by our failed search for linguistic meaning), as discussed in section VI.C.4 below, to determine the legal effect of such failure to find speaker meaning. We must do this because adjudication demands resolution of disputes and thus cannot be satisfied without determination of meaning. As discussed in section VI.C.4.b below, construction is better-informed when it considers prior searches

162. GREENAWALT, supra note 146 , at 49.

163. Taking this further, the flexible logic of metaphor, for example, is essential to human thought and communication. See Harold A. Lloyd, Law as Trope: Framing and Evaluating Conceptual Metaphors, 37 PACE L. REV. 89, 99-101 (2016). Thus, we both say that "time flies" (where time is mobile) and "we have made it through another week" (where time is stationary and we move instead). Id. at 100 (quoting GEORGE LAKOF \& MARK JOHNSON, PHILOSOPHY IN THE FLESH 52 (1999)). For a detailed table outlining such metaphorical variation, based upon early childhood experience or later construction, see id. at 109-14. 
for actual speaker meaning, and the search for speaker meaning thus serves a critical function even where such meaning ultimately proves indiscernible.

\section{b. Standards of Proof}

In weighing evidence under the Principle of Speaker Meaning, one must of course use an appropriate standard of proof for determining meaning. Although higher standards than preponderance of the evidence (such as clear and convincing evidence) are usually required to use parol or extrinsic evidence "to contradict, modify, or vary the terms of a written contract, or of a bill of lading, a deed, a lease, a note, a receipt, or a will,"164 the Principle of Speaker Meaning would encourage careful reflection upon whether such heightened standards of proof should generally apply in such cases as a matter of interpretation. Do we truly want a heightened burden of proof that would give more weight to text when other evidence of speaker meaning might be more compelling as a matter of interpretation? The Principle of Speaker meaning would thus encourage careful reflection upon whether we should use standards other than a preponderance of the evidence when performing interpretation. ${ }^{165}$

\section{Defaults to Construction}

\section{a. Adjudication Demands Resolution}

Where we cannot reasonably make linguistic sense in given cases of mixed or otherwise-inconsistent meaning, or where we cannot find any reasonably discernible speaker meaning, we must then turn to construction to determine the legal effect of such failure to find speaker meaning. Again, adjudication demands resolution of disputes, and construction enlightened by our failed search for linguistic meaning is the only remaining solution in such cases.

\section{b. Interpretation Attempts Enlighten Construction}

Under the Principle of Speaker Meaning, such construction of meaning should be enlightened by the failed attempt at interpretation for at least two reasons. Again, to the extent possible, we should attempt to respect speakers' linguistic meanings for the reasons discussed in sec-

164. 32A C.J.S. Evidence $§ 1625$ (2020); see id. $\$ 1615$ (noting that the preponderance of the evidence standard is the default standard in civil cases unless a higher standard is "necessary to protect important rights").

165. The question of the appropriate standard of proof for interpretation is different from questions of standards of proof that construction should demand in particular cases. Due to space limitations, I also generally leave this topic for another day. I do, however, explore in section VI.D.2 infra the possible limitations on adversely construing meanings of criminal defendants. 
tion VI.C.2. Additionally, even failed attempts at discerning speaker meaning can enhance construction of speaker meaning. For example, if a vendor offers "fish" for sale in semantically-unresolvable ways that suggest both (1) the catch of the day (except for trout) and (2) only flounder, construction of the offer should not include trout even though we cannot otherwise resolve as a matter of actual speaker meaning whether the offer is for only flounder or for a differing catch of the day other than trout.

\section{c. A Rebuttable Presumption of Rationality}

Additionally, since speakers who are willing to be bound by their offers presumably want their offers to be performable (and contradictory offers are not performable to the extent they require the contradictory), the Principle of Speaker Meaning holds that construction should presume that sellers intend to speak rationally unless the evidence establishes the contrary. This presumption can be similarly extended to all forms of legal speech acts since most speech actors presumably intend that their legal speech acts work and are thus coherent. Of course, not all speech actors have such intent and thus the Principle of Speaker Meaning makes this a rebuttable presumption.

\section{d. Construing Meaning When Speaker Meaning Is Not Fully Discernible}

These observations can help us formulate a reasonable approach to the construction of meaning when speaker meaning is not reasonably fully discernible. Such construction of meaning should strive to respect the speaker's meaning to the extent possible in light of applicable law and lawful policy. It should thus (1) be enlightened by evidence of actual speaker meaning even if such evidence does not suffice to fully determine actual speaker meaning; (2) presume the rationality of the speaker unless the evidence proves otherwise; and (3) act accordingly when following any applicable law and lawful policy governing construction.

Thus, in the fish example above, trout would be excluded since it would be inconsistent with the available evidence. Additionally, the speaker should be presumed rational if the evidence does not indicate otherwise. The conflicting evidence of fish offered for sale can indicate speaker error rather than speaker irrationality, and one instance of mixed evidence hardly seems sufficient evidence of an irrational speaker. Presuming such rationality (and also attempting to construe meaning that is most consistent with all the evidence) requires construing a meaning that threads both such needles. Construing a meaning of flounder when caught as the fish of the day would seem to thread both needles and could thus be a reasonable construction. The Principle of Speaker Meaning does not claim that the above approach 
will generate only one reasonably possible construction of meaning in every case. Various cases may generate multiple reasonable constructions of meaning, and judges must exercise their practical wisdom in determining the most appropriate, reasonable construction of meaning. In section VI.D below, I will return in more detail to the use of the Principle of Speaker Meaning in both public and private law

\section{The Incorporation Caveat}

As a caveat, however, to the Principle of Speaker Meaning, such principle recognizes that a speaker can incorporate the concepts of others without intending to modify such concepts. In such a case, the incorporated concepts remain unmodified and thus unfold over time as unmodified by the incorporating speaker. For example, if the drafters of the Declaration of Independence meant to incorporate an independent "self-evident" concept "that all men are created equal," the incorporated "self-evident" meaning would govern here. In such a case, if a drafter himself believed that only white men fell under the concept of equality, that belief would by definition not limit the externally incorporated concept.

Thus, in interpreting the Declaration of Independence, it would be a mistake in such a case to give weight to what a drafter himself meant by the incorporated concept of equality of men in the Declaration of Independence unless he instead meant to put his own differing meaning on the concept. Instead, we should examine the philosophical and religious traditions in which this notion arose and examine the relevant speakers and their meanings in such traditions. We can call this recognition of the possibility of incorporation the "incorporation caveat," and for the sake of space I will consider this incorporation caveat an unstated caveat running through the remainder of this Article.

\section{The Concept/Conception Distinction}

Another caveat to the Principle of Speaker Meaning is that one must distinguish between concepts and conceptions. For example, a speaker may have a concept of an automobile as a self-propelled transportation vehicle having four wheels and operating on paved roadways. When using that concept, however, a speaker may always have a particular conception in mind of a silver 2012 Prius. That conception, however, is not to be confused with the speaker's broader concept of automobile. Thus, if that speaker bequeaths to a friend all of his "automobiles," that term would not be limited to silver 2012 Priuses. I return to this distinction in section VI.D.4.b.vi below. 


\section{Whose Meaning Controls: Some Applications of Interest to Lawyers}

In light of the discussions above, I shall now apply and test the Principle of Speaker Meaning using several types of nonfiction speech acts of interest to lawyers. Where useful, I shall also contrast construction with interpretation.

\section{Signs, Assertives, and Tort Law}

I begin with a simple hypothetical to lay the groundwork for more complex discussions that follow. Let us imagine that we have a reasonably discernible speaker who, for example, asserts that "John Smith is a thief." The Principle of Speaker Meaning requires us to seek the actual speaker's meaning (as it unfolds over time) if the actual speaker has communicated such meaning with reasonable discernibility. Unless there is reasonably discernible evidence that the speaker meant to speak ironically and not literally, we should interpret the speech as an assertion that Smith is a thief. If, however, the reasonably discernible evidence suggests such irony, we should interpret such speech ironically.

However, as a matter of construction, we might reach a different result. If our speaker's irony takes on a literal meaning in the general public that harms Smith in a way that we feel defamation law should discourage, we might as a matter of such law construe the legal effect of the words literally. For lack of space, I take no position here on the propriety of doing so. I raise the point merely to make the logical distinction between interpretation and construction of individual assertive speech acts so that we might build upon the distinction in the discussion that follows.

\section{Signs, Commissives, and Criminal Law}

In Elonis $v$. United States, 166 the defendant posted online a semiotic array of items which on their face could be seen as threatening. For example, mixing the indexical, iconic, and symbolic, the defendant posted a photograph (index) of a co-worker and himself where he held a toy knife (icon) to the neck of the co-worker and included the caption "I wish" (symbol). ${ }^{167}$ After he was subsequently fired, the defendant post-

166. 135 S. Ct. 2001 (2015). See also Lawrence M. Solan, Linguistic Knowledge and Legal Interpretation: What Goes Right, What Goes Wrong, in THE NATURE OF LEGAL INTERPRETATION: WHAT JURISTS CAN LEARN ABOUT LEGAL INTERPRETATION FROM LINGUISTICS AND PHILOSOPHY 66,71-72 (Brian G. Slocum ed., 2017).

167. Elonis, 135 S.Ct. at 2005. 
ed such language as "Y'all think it's too dark and foggy to secure your facility from a man as mad as me?"168

The defendant also posted about his wife. Such posts included: "Did you know that it's illegal for me to say I want to kill my wife?"169 After his wife obtained a "three-year protection-from-abuse order" against the defendant, the defendant posted the following online:

Fold up your [protection-from-abuse order] and put it in your pocket

Is it thick enough to stop a bullet?

Try to enforce an Order

that was improperly granted in the first place

Me thinks the Judge needs an education

on true threat jurisprudence

And prison time'll add zeros to my settlement ...

And if worse comes to worse

I've got enough explosives

to take care of the State Police and the Sheriff's Department. 170

The defendant also posted:

That's it, I've had about enough

I'm checking out and making a name for myself

Enough elementary schools in a ten mile radius

to initiate the most heinous school shooting ever imagined

And hell hath no fury like a crazy man in a Kindergarten class

The only question is . . . which one?171

As a result of these and other posts, the defendant was charged and convicted under 18 U.S.C. $\S 875(\mathrm{c})$, which criminalizes the transmission in interstate commerce of "any communication containing any threat . . . to injure the person of another."172

How should the Principle of Speaker Meaning apply here? Although his wife and former co-workers were "afraid and viewed [the defendant's] posts as serious threats," 173 the speaker's intent governs linguistic meaning here for the reasons discussed above. This, again, is a separate question from (1) construction of legal meaning (as when, for example, a statute construes a contractual price as a reasonable price when the parties have not specified their price) and (2) the wisdom or appropriateness of speaker meaning as a moral or social matter. Thus, as a matter of interpretation, we must examine evidence of actual speaker meaning, including but not limited to the words as evidence, to determine such linguistic meaning.

168. Id.

169. Id.

170. Id. at 2006

171. Id.

172. Id. at 2004 (quoting 18 U.S.C. $\S 875(c)$ ).

173. Id. at 2007. 
Among other things, holding a toy knife to someone's throat and using words such as "kill" and "bullet" can no doubt be possible evidence of contempt for the defendant's co-workers and wife as well as possible evidence of threatened harm. However, statements posted by the defendant (such as "Art is about pushing limits"174) and words uttered by the defendant in court (such as claims that his posts modeled wellknown rap lyrics ${ }^{175}$ ) might suggest artistic intent- though many, if not most, of us might find such artistic intent a difficult sell. ${ }^{176}$ As to linguistic meaning, depending on analysis of all other evidence in the case, we might interpret the speaker's meaning as committing a threat. We might also find the meaning as mixed or even incoherent given the potentially conflicting evidence. If we find mixed meanings, we might find some of the meanings as committing threats while others do not. On the other hand, we might be unable to reasonably interpret either the parts or the whole in light of the interactions of such mixed meanings. When speaker meaning is not reasonably discernible for this or other reasons, such as lack of evidence, as noted in section VI.C.4 above, we must turn to construction to determine meaning and its legal effects.

Additionally, even where speaker meaning is reasonably discernible, where a statute applies we must also construe the legal effects of such meaning. Thus, 18 U.S.C. $\S 875(\mathrm{c})$ requires construction of the legal meaning and effects of (1) the posts and (2) any relevant speaker intent, however discernible. ${ }^{177}$

Here, the district court convicted the defendant of threats under the statute, holding that conviction "required only that [the defendant] intentionally made the communication, not that he intended to make a threat." 178 The court of appeals upheld the conviction, holding that the statute only required "the intent to communicate words that the defendant understands, and that a reasonable person would view as a threat."179 The Supreme Court reversed and remanded, focusing on the jury instruction "that the Government need prove only that a reasonable person would regard [the defendant's] communications as threats." 180 Rejecting this approach as effectively substituting a negligence standard for the criminal intent typically required by criminal statutes, the Supreme Court found such criminal intent would be "satisfied if the defendant transmits a communication for the purpose of

174. Id. at 2006.

175. Id. at 2007.

176. The speaker could also intend the same words to express contempt, threats, and forms of the aesthetic.

177. Again, for the reasons set forth in section VI.C.2 and section VI.C.4.b, infra, this in no way diminishes the importance of interpretation and discerning speaker meaning where reasonably possible.

178. Elonis, 135 S. Ct. at 2007.

179. Id.

180. Id. at 2012. 
issuing a threat, or with knowledge that the communication will be viewed as a threat." 181

The tests for legal meanings recognized in the various stages of this case thus differ greatly. At odds with the Principle of Speaker Meaning, the district court required no intended threat, ${ }^{182}$ while the Supreme Court, somewhat more in line with the Principle of Speaker Meaning, required speaker "purpose" or "knowledge," holding, again, that the criminal mental state required by the statute is met if the defendant communicates "for the purpose of issuing a threat, or with knowledge that the communication will be viewed as a threat." 183

Given the high stakes of a criminal conviction here, the Supreme Court's focus on the speaker's intent or mental state makes sense. It also makes sense that we should, in general, have less flexibility in construing meaning that a criminal defendant might not have meant. Thus, construction should insist on proof beyond a reasonable doubt rather than by a preponderance of the evidence when establishing a speaker's criminal intent to convey a threat. We can therefore have cases like Elonis where we might well believe that there was a linguistic threat while nonetheless finding no such threat as a matter of criminal construction. ${ }^{184}$

\section{Signs, Commissives, and Private Law}

Having first explored a public law example of potential commissives, we can now turn to some private law examples. In exploring whose meaning should control in cases of private law commissives, I will briefly examine the interpretation and construction of wills and then turn to the interpretation and construction of contracts.

181. Id. at 2011-12 (holding that "Federal criminal liability generally does not turn solely on the results of an act without considering the defendant's mental state" and noting Cochran v. United States, 157 U.S. 286, 294 (1895), which held that a defendant could encounter "liability in a civil action for negligence, but he could only be held criminally for an evil intent actually existing in his mind.") The Court thus reversed and remanded the case. Id. at 2013 .

182. Id. at 2007.

183. Id. at 2012 . I say "somewhat more in line" because the "knowledge" prong of this test may deviate from the Principle of Speaker Meaning to the extent such prong recognizes unintended commissives. For example, one might genuinely write verse with no intent to threaten anyone while knowing that some will nonetheless feel frightened. See Solan, supra note 166, at 7172 (noting fright as "a side effect"). That said, of course, we might have legal, lawful policy or other lawful reasons for finding a threat as a matter of construction just as we might construe ironic speech as defamatory as suggested in section VI.D.1 supra.

184. As Solan notes: "the Supreme Court made it clear that proving that Elonis intended his wife to draw inferences that would cause her to be intimidated was necessary to establishing that a crime has been committed. Until then, the literal meaning of these verses would be taken at face value." Solan, supra note 166 , at 72. 


\section{a. Signs and Wills}

I treat wills as commissives because they commit the testator's estate to do certain things. In the case of a single testator, it is hard to disagree with Greenawalt that "the intentions of the writer who has died are obviously key, since the will is designed to carry out her intentions." 185 From the standpoint of interpretation, it is therefore hard to see how the right linguistic meaning is not the meaning of the author of the will, i.e., the speaker's or author's meaning. In this regard, Professor Greenawalt gives us the example of the testator who named in his will a person he did not know, "Robert J. Krause," rather than "Robert W. Krause," a "close friend and employee." 186 Because this apparently involved mistaken reliance on a telephone book, the court followed the author's more likely intent. ${ }^{187}$ In light of the Principle of Speaker Meaning, the court's action seems quite correct as a matter of interpretation since there was reasonable evidence of which of the two Krauses had a close relationship to the testator. Again, since the purpose of a will is to dispose of a testator's property as the testator intends, ${ }^{188}$ it runs afoul of such purpose to substitute for the actual author's meaning the meaning of some hypothetical ideal author or the meaning of readers whether actual or hypothetical.

As for construction of the legal meaning of the will, one can strongly argue that construction should not reach a different result. Robert J. Krause was presumably not relying on receiving the property at issue so no reliance concerns should generate a different legal meaning. Additionally, as Greenawalt points out, reliance arguments in the case of wills can often seem of little weight since a testator can generally change his will at will (no pun intended), and "most potential recipients do not actually see the wills of their benefactors." 189

Potential reasons for construing the meaning in favor of Robert J. Krause as written-such as (1) will drafters' and courts' need for "clear and consistent interpretations of similar language," (2) the difficulty of "discerning after someone's death what was really intended," and (3) guarding against the possibility that evidence of different meanings of

185. GREENAWALT, supra note 146, at 11. Greenawalt observes that matters may be more complex "if a married or unmarried couple has reached an agreement about what the will of each would provide. In that event, one might see a will as more like a contract." Id. For sake of space, I will keep my discussion of will to that of a single testator who has made no such agreement, and I will discuss contracts in a separate section below.

186. Id. at 15.

187. Id. Such result can be seen as either a "correction" of the will or applying the proper meaning of the signifier "Robert J. Krause." Although either frame reaches the correct result, from a semiotic standpoint it would seem more precise to say that the court sought the correct meaning of the signifier "Robert J. Krause."

188. See id. at 11 .

189. Id. at 15 . 
terms such as "Robert J. Krause" could be manipulated190_do not apply here. Names vary so there is no "similar language" to construe consistently. Furthermore, it should not be difficult to determine that the testator employed and was close friends with Robert W. Krause rather than Robert J. Krause. Given all this, there is little reason to worry about improper manipulation of meaning when recognizing that "Robert J. Krause" really meant the testator's employee and close friend, Robert W. Krause. Construction should thus converge with interpretation in finding such a meaning.

b. Signs and Contracts: Williston, Corbin, and More

\section{i. A Case of Apples}

One can imagine a case where both a seller and a buyer intend "apples" to mean only golden delicious apples. If that seller agrees to sell such "apples" to that buyer upon written lawful terms which both parties are using in the same way, the parties' linguistic meaning of "apples" no doubt covers only golden delicious apples. Applying a different meaning of some hypothetical speaker of English or of some other reader (actual or hypothetical) would change what the parties meant and would thus fail as a matter of interpretation.

This seems straightforward, and Steven J. Burton tells us that "American courts universally say that the primary goal of contract interpretation is to ascertain the parties' intentions at the time they made their contract." 191 To the extent the parties' intentions are reasonably discernible, the Principle of Speaker Meaning squarely accords with this "primary goal" and with interpreting "apples" in the contract above to mean golden delicious apples.

As for construction, it is also difficult to justify (without more) a different meaning for "apples" here. In construing contracts, courts may, of course, recognize other goals than enforcing speaker meaning. Such goals include: (1) fostering "the security of transactions," including clarity for the parties and their assignees "about their rights, duties, and powers;" (2) fostering "the peaceful settlement of disputes nonarbitrarily, in accordance with the Rule of Law," which includes predictable contract interpretation that is "coherent with the law of contracts generally;" and (3) "formulating legal rules that are administrable by the courts and by the parties." 192

190. See Greenawalt, supra note 154 , at 50.

191. STEVEN J. BURTON, ElEMENTS OF CONTRACT INTERPRETATION 1 (2009).

192. See id. at 2, 7-8. See also GREENAWALT, supra note 146, at 6, 111 (noting concerns such as judges being asked to perform functions they cannot reasonably perform, respecting needs of a "just and healthy society," and "general fairness and efficiency"). 
Here, however, the seller and buyer are the only parties affected by the contract, and their meaning of "apples" is reasonably discernible. Construing the contract in accordance with their meaning secures their deal, fosters peaceful and non-arbitrary dispute settlement by treating the parties as they intended, and proves to be administrable by turning on reasonably discernible meaning and requiring that the parties act just as they intended.

ii. Contracts: Literalism, Objectivism, and Subjectivism

Having addressed both interpretation and construction of the "apples" contract above, we can now turn to three schools of thought addressing the reading and enforcement of contracts.

First, "literalism . . . holds that the literal meaning of the contract's governing word or phrase, as found in a dictionary, determines the parties' rights, duties and powers."193

Second, "objectivism . . . looks for the parties' intentions as expressed (manifested) in the contract document as a whole and its objective context, but not the parties' mental intentions;" in other words, it looks for "manifested intention, as a reasonable person familiar with the objective circumstances would understand the manifestations," and thus "infers reasonable meaning(s) from the parties' manifestations of intention in light of the circumstances, whether or not the meaning(s) reflect what the parties had in mind as the meaning of the terms they used."194 Thus, for example, Samuel Williston looks to "the natural meaning of the writing to parties of the kind who contracted at the time and place where the contract was made, and [under] such circumstances as surrounded its making."195

Third, "subjectivism . . . looks for the mental intentions or knowledge of the parties when they manifested their intentions, taking into account all relevant evidence," although it does not recognize intentions which are not expressed.196 Thus, the Restatement (Second) of Con-

193. BURTON, supra note 191, at 2 .

194. Id. at $2,6,51$.

195. Id. at 29 (quoting 4 SAMUEL L. WILLISTON, WILLISTON ON CONTRACTS $\S$ 607 (3d ed. 1957)).

196. Id. at 2, 28; see also GREENAWALT, supra note 146, at 23-24 (discussing the Restatement (First) of Contracts' "complex objective approach" turning on the "meaning that would be attached ... by a reasonably intelligent person acquainted with all operative usages and knowing all the circumstances . . . other than oral statements by the parties of what they, intended the words to mean[]" and the Restatement (Second) of Contracts "more subjective approach"); RESTATEMENT (FIRST) OF CONTRACTS \& 230 (AM. LAW INST. 1932); RESTATEMENT (SECOND) OF CONTRACTS § 201 (AM. LAW INST. 1981). Additionally, the RESTATEMENT (SECOND) OF CONTRACTS § 212 cmt. a (AM. LAW INST. 1981) notes that "the relevant intention of a party is that manifested by him rather than any different undisclosed intention." The First Restatement reflects Williston's objectivism while the Second Restatement reflects Arthur Corbin's greater subjectivism. See KENT GREENAWALT, LEGAL 
tracts provides: "Where the parties have attached the same meaning to a promise or agreement or a term thereof, it is interpreted in accordance with that meaning." 197

As phrased, the literalism option can be quickly dispatched for both interpretation and construction. Since words typically have multiple definitions and can thus have multiple "literal" senses, literalism cannot work as a matter of interpretation. Even if parties to a contract have used terms in a dictionary sense, the dictionary (with its multiple definitions of terms) cannot itself tell us which sense the parties used. Additionally, literalism would lead us astray where parties have not used terms in a standard or "dictionary" sense. Literalism fairs no better with construction. Given multiple "literal" definitions of terms, construction also requires more than just a dictionary. If a judge is to construe contracts in accordance with the dictionary meanings of terms, a judge must have some method of determining which of these "literal" dictionary meanings apply.

Objectivism also fails for both interpretation and construction. Since it would divorce itself from the parties' "mental intentions," and, in Williston's words, would look for "the natural meaning of the writing to parties of the kind who contracted at the time and place where the contract was made, and [under] such circumstances as surrounded its making"198 rather than what the parties actually meant, such "objectivism" cannot work as a general rule of interpretation. If the parties' meaning is reasonably ascertainable, interpretation should give them that meaning for the reasons set forth in section VI.C above. Objectivism also fails as a general rule of construction. Again, if the seller and buyer are the only parties affected by the "apples" contract and their meaning of "apples" is reasonably discernible, why should they not have their contract for golden delicious apples? Again, construing the contract in accordance with their meaning secures their deal, should foster peaceful and non-arbitrary dispute settlement by treating the parties as they intended, and should prove quite administrable by turning on reasonably discernible meaning and requiring that the parties act just as they intended.

Of the three approaches above, this leaves us with "subjectivism," the approach which "looks for the mental intentions or knowledge of the parties when they manifested their intentions, taking into account all relevant evidence." 199 As an approach to interpretation, this approach, on its face, accords with the emphasis that the Principle of Speaker Meaning places upon speaker meaning. As a matter of construction, this approach would also give the seller and buyer in the

INTERPRETATION: PERSPECTIVES FROM OTHER DISCIPLINES AND PRIVATE TEXTS 265-67 (2010).

197. RESTATEMENT (SECOND) OF CONTRACTS § 201(1) (AM. LAW INST. 1981).

198. BURTON, supra note 191, at 29.

199. Id. at 2 . 
"apples" contract above their contract for golden delicious (and only golden delicious) apples. In doing so, this approach would also construe the contract in accordance with the parties' meaning, securing their deal. It would likely foster peaceful and non-arbitrary dispute settlement by treating the parties as they intended, and should prove highly administrable by turning on reasonably discernible meaning and by requiring that the parties act just as they intended. Common construction policies are thus advanced by such an approach.

Thus, the Restatement (Second) of Contracts correctly interprets and construes the following similar example:

$\mathrm{A}$ and $\mathrm{B}$ are engaged in buying and selling shares of stock from each other, and agree orally to conceal the nature of their dealings by using the word "sell" to mean "buy" and using the word "buy" to mean "sell." A sends a written offer to B to "sell" certain shares, and B accepts. The parties are bound in accordance with the oral agreement. 200

This example squarely accords with the Principle of Speaker Meaning to the extent the parties' odd use of terms is reasonably ascertainable. As for construction, recognizing the parties' meaning secures their deal, should foster peaceful and non-arbitrary dispute settlement by treating the parties as they intended, and, again, should prove quite administrable by turning on reasonably discernible meaning and by requiring that the parties act just as they intended.

A change of facts could, of course, change this result as a matter of both interpretation and construction. For example, as a matter of interpretation, if $\mathrm{A}$ and $\mathrm{B}$ both die and their heirs are left to settle the contract, A's and B's speaker meaning may no longer be reasonably discernible. ${ }^{201}$ If such speaker meaning is no longer reasonably discernible, then construction would step in to determine the meaning and its legal effects.

Even where linguistic meaning is reasonably discernible, construction can nonetheless result in a legal meaning of contract terms that differs from their linguistic meaning. Again, in enforcing contracts, courts may recognize other goals than respecting speaker meaning, such as: (1) fostering "the security of transactions," including clarity for the parties and their assignees "about their rights, duties, and powers;" (2) fostering "the peaceful settlement of disputes non-arbitrarily,

200. RESTATEMENT (SECOND) OF CONTRACTS $§ 212 \mathrm{cmt}$. b, illus. 4 (AM. LAW INST. 1981); see also BURTON, supra note 191, at 28.

201. Again, the RESTATEMENT (SECOND) OF CONTRACTS § 201(1) (AM. LAW INST. 1981) provides: "Where the parties have attached the same meaning to a promise or agreement or a term thereof, it is interpreted in accordance with that meaning." However, again, the RESTATEMENT (SECOND) OF CONTRACTS $\S$ 212 cmt. a (AM. LAW INST. 1981) also notes that "[T] he relevant intention of a party is that manifested by him rather than any different undisclosed intention." In this changed hypothetical, to use the RESTATEMENT (SECOND) terminology, the original "manifested" intent may no longer be discernible. 
in accordance with the Rule of Law," which includes predictable contract interpretation that is "coherent with the law of contracts generally;" and (3) "formulating legal rules that are administrable by the courts and by the parties." 202

Under these changed facts where the death of A and B leaves their original speaker meaning no longer reasonably discernible, these construction goals may well require construing "buy" to mean "buy" and "sell" to mean "sell." Fostering peaceful resolutions of disputes may itself suffice for such construction where there is no reasonably discernible evidence that such terms were used in their opposite senses.

A different change of facts could also raise construction concerns, such as promoting "security of transactions." If, for example, the contract is assigned while A and B are still living, and the assignee does not know that A and B had orally agreed to alter the meanings of "buy" and "sell," promoting "security of transactions" strongly weighs in favor of construing "buy" to mean "buy" and "sell" to mean "sell" to protect the "innocent" assignee. Since the assignor (A or B) would be in a superior position of knowledge, the assignor in such a case should be forthright in informing the assignee of any special meaning of terms. ${ }^{203}$

\section{Signs and Directives}

In exploring whose meaning should govern in the case of directives, I next explore the question of legislation and speaker meaning. For the reasons discussed below, the Principle of Speaker Meaning should again control interpretation where reasonably possible. For reasons of space, I limit my discussions here to interpretation and do not explore construction.

\section{a. Signs and Legislative Intent}

To apply the Principle of Speaker Meaning in legislation, we must be able to identify the relevant speaker and speaker intent. This is, of course, more complex than identifying the speaker and speaker intent in the case of a single testator or in the case of the two individual parties to the "apples" contract above. Given the multiple parties involved in legislation-the legislators and the executive who signs such legisla-

202. BURTON, supra note 191, at 2, 7-8; see also GREENAWALT, supra note 146, at 6, 111 (noting concerns such as judges being asked to perform functions they cannot reasonably perform, respecting needs of "a just and healthy society," and "general fairness and efficiency").

203. Thus, where parties have differing meanings as to terms, the RESTATEMENT (SECOND) OF CONTRACTS § 201(2) sensibly addresses such differing meanings in terms of which party is at fault, and $\$ 201(3)$ recognizes no mutual assent where meanings differ and neither party knew the other's meaning or should have known such meaning. See also BURTON, supra note 191, at 62,62 n.109. 
tion, not to mention staff and others who may be involved in drafting legislation-identifying the relevant speaker and speaker intent may seem daunting and even impossible. Additionally, since a legislature is not itself a thinking being, we might ask whether it can ever make logical sense to speak of a legislature as a speaker or to speak of a legislature's intent.

\section{b. Signs and Legislatures as Speech Actors}

In tackling these issues, we should remember that we create our concepts and that we judge them by their workability. ${ }^{204}$ We should thus recognize with Gerald MacCallum, Jr., that the question here is not just "Are legislatures capable of intent?" We should also be asking whether the notion of legislative intent is useful. ${ }^{205}$ If such a concept is useful, we should fashion a concept of legislative intent in a way that works most effectively.

Such a concept is no doubt useful. It continues (and helps us grapple with) a long judicial tradition of seeking "legislative intent," a tradition that respects the "principle of legislative supremacy" by recognizing the supremacy of laws enacted by the legislature. ${ }^{206}$

Additionally, understanding "legislative intent" as part of a legislative speech act is consistent with Constitutional references to Congress as an actor. For example, Article I speaks of "legislative Powers" that are "vested in" Congress, and speaks of each house of Congress being the "Judge of the Elections, Returns and Qualifications of its own Members." 207 How can we speak of Congress as such a rational Constitutional actor if we cannot also find a way to speak of its having intent to act in certain ways?

\section{i. Signs and Legislatures' Speech Acts}

We must, then, find a workable way of speaking of legislative intent. Consistent with the recognition above that we speak of legislative institutions (such as Congress) as both acting and as having intent, I

204. Lloyd, supra note 27, at 264-74 (discussing workability).

205. See GERALD C. MACCALLUM, JR., LEGISLATIVE INTENT AND OTHER ESSAYS ON LAW, POLITICS, AND MORALITY 34-35 (Marcus G. Singer \& Rex Martin eds., 1993). Some would go further than such pragmatic inquiry and maintain that the concept of legislative intent is too entrenched in our common discourse to be entirely avoided. See L. M. SolAn, THE LANGUAGE OF STATUTES : LAWS AND THEIR INTERPRETATION 115 (2010) (hereafter SOLAN, LANGUAGE OF STATUTES) ("I do not believe that any judge or commentator can consistently maintain that courts should dispense altogether with discussion of legislative intent. The concept is just too deeply embedded in the way we see the world.")

206. M.B.W. Sinclair, Legislative Intent: Fact or Fabrication?, 41 N.Y.L. ScH. L. REV. 1329, 1331 (1997). See also Solan, LANGUAGE OF STATUTES, supra note 205, at 118 ("intent is a rule-of-law value.")

207. U.S. CONST. art. I, $\S \S 1,5$. 
would find legislatures themselves (not some combination of legislators) as the relevant speakers or speech actors. Consistent with that approach, I would then maintain that a legislature's legislative (and thus directive) speech act occurs when a sufficient majority of legislators have voted in the manner provided by law to pass a legislative proposal offered for debate. ${ }^{208}$

In other words, a legislature itself speaks legislatively upon the passage in the manner provided by law of legislative proposals offered for debate. ${ }^{209}$ I would thus sympathize with Richard Ekins' claim that instead of a "sum of the intentions held by each member of the majority," "what is held in common amongst legislators" is a common "proposal" they deliberate and vote upon. ${ }^{210}$ I would use "common" here to refer to the group activity involved in debating and voting upon such proposals. That said, the question thus becomes what is the meaning of such a group proposal that, when passed, becomes the legislative speech act of the legislature. ${ }^{211}$

\section{ii. Signs and Interpreting Legislatures' Speech Acts ${ }^{212}$}

To answer this question, we necessarily turn to the concepts and conceptual frameworks used by the legislators in the legislative process to the extent such concepts and conceptual frameworks are reasonably discernible. ${ }^{213}$ For if bills use concepts and conceptual frame-

208. See Bill, BLACK'S LAW DiCTIONARY (7th ed. 1999); RICHARD EKINS, THE NATURE OF LEGISLATIVE INTENT 230-31 (2012); WILLIAM J. KEEFE \& MORRIS S. OGUL, THE AMERICAN LEGISLATIVE PROCESS 37-41 (8th ed. 1993) (summarizing and diagramming how "a bill becomes a law").

209. See EKINS, supra note 208, at 230-31.

210. Id. at 231.

211. As Peirce reminds us, "nothing is a sign unless it is interpreted as a sign." 1 \& 2 PEIRCE, supra note 7, at 2.306. Thus, we must ask whose interpretation controls and we cannot fail to address that question when we speak of a common "proposal" along the lines of Ekins. See EKINS, supra note 208, at 231. Additionally, though any such legislative proposal will have been passed at a specific point in time, that is not to say that better and fuller understandings of such legislative speaker meaning cannot thereafter develop over time, or that such speaker meaning itself does not unfold over time. See infra Part VIII.

212. In addition to the linguistic meaning of a statute, construction of the statute can (as in the case of other speech acts) provide a legal meaning different than the linguistic one. For example, in accordance with the lenity canon, a court might construe a statute more narrowly than its linguistic meaning. See WILLIAM D. POPKIN, A DICTIONARY OF STATUTORY INTERPRETATION 191-93 (Carolina Acad. Press 2007). Thus, a court might construe a criminal statute in favor of "modern reader understanding", in light of the "general principle that people should receive "fair warning' of what behavior is criminal." See GREENAWALT, supra note 146, at 63.

213. See supra note 203 and accompanying text. Again, though any such legislative proposal will have been passed at a specific point in time, that is not to say that better and fuller understandings of such legislative speaker meaning cannot thereafter develop over time, nor that such speaker meaning itself does not unfold over time as discussed in Part VIII, nor that construction cannot provide different meanings over time. 
works other than those used by the legislators involved in the legislative process, ${ }^{214}$ those legislators would have debated and voted upon concepts and conceptual frameworks other than the ones they debated and voted upon. That would be nonsense, not to mention inconsistent with the very notion of legislative consideration and debate. ${ }^{215}$

Additionally, using meanings assigned by other speakers or hearers would effectively usurp the legislators' role. As Michael Sinclair puts it, "[l] egislators are elected . ... . [and t]o allow [a] 'hearer's' meaning to triumph ... would be anti-democratic and would allow the triumph of non-elective law making over the normal, elective law-making."216

\section{iii. A "Dozen" Cakes}

Thus, one can imagine legislators debating and passing a bill regulating the price of a "dozen" cakes where the term "dozen" is used by all the legislators to mean "twelve." The legislators' linguistic meaning would thus not include other meanings such as a baker's dozen (thirteen). This would hold even though a baker's dozen might have been a more common meaning in reference to cakes at the time, even though a reasonable non-legislator reader (whatever that might mean) of the time might have understood "dozen" here to mean a baker's dozen, and even though the executive signing the legislation into law might have understood dozen here to mean a baker's dozen. A different understanding by such executive cannot, consistent with rule of law, change the meaning of such a passed bill. Allowing such a change of meaning would effectively shift legislative functions to the executive branch by allowing the latter to alter the meaning of legislation and thereby, in effect, to act legislatively. Additionally, allowing such a change would again have the nonsensical result of legislators having debated and voted upon meanings they did not debate and vote upon.

Consistent with the Principle of Speaker Meaning, the conceptual framework used by the legislators' thus gives us the initial meaning of the legislation, which meaning is then unleashed into experience to develop through time as discussed in Part VII below.

214. These meanings, under the applicable contexts, could of course differ from "dictionary" or other non-legislator meanings.

215. The legislators thus provide the necessary derivative meaning for the words and meanings debated. See supra sections I.B \& VI.B.2.; see also SEARLE, supra note 13, at 27-29 (on derived intentionality). Again, this is not to say that better and fuller understandings of such legislative speaker meaning cannot thereafter develop over time, nor that such speaker meaning itself does not unfold over time as discussed infra Part VIII, nor that construction cannot provide different meanings over time.

216. See Sinclair, supra note 206, at 1388. 
iv. Mixed or Indiscernible Meaning

Of course, we can have situations where discerning speaker meaning can be more difficult than in the example above, and can, in fact, even be impossible. For example, as Professor Slocum notes, "due to the enormous volume of legislation and other reasons, most legislators do not read most of the text of the statutes on which they vote."217 To the extent this is true, one might despair of ever finding how legislators used terms.

However, one must remember that all forms of relevant context constitute evidence ${ }^{218}$ as further explored in the Monarch case in Section VI.D.4.b.v below. Such context, for example, may show that legislators who did not read the text may have adopted or incorporated the meaning of others more actively involved in drafting the text. ${ }^{219}$ To the extent we can find any evidence of such speaker meaning (including contextual or other evidence) when performing interpretation, the Principle of Speaker Meaning requires giving such evidence weight for the reasons discussed above, including rule of law reasons that require avoiding the improper "triumph of non-elective law making." 220

As I have written before, the pragmatics of finding speaker meaning is often complex, and reasonable minds can often disagree as to the results of such a process. ${ }^{221}$ Not only is this the case with ordinary judges of speaker meaning, it is also the case with judges having the characteristics of the "ideal" judge Eunomia. ${ }^{222}$ Law, however, requires answers in particular cases, and we must do our best to find and provide such answers in a way that, again, avoids an improper triumph of nonelective law making." 223

217. Slocum, Contribution of Linguistics, supra note 148, at 33.

218. Thus, the Principle of Speaker Meaning would look to legislative history to the extent relevant and would consider as part of the legislative cognitive and discourse context "materials from the process of enactment that indicate how a bill is understood" and would consider "[t]he primary [such materials to be] reports of committees that screen and revise bills, statements made by sponsors on the floor of the legislature about what bills mean, and actual changes in the texts of bills as they proceed towards passage." See Kent Greenawalt, Constitutional and Statutory Interpretation, in THE OXFORD HANDBOOK OF JURISPRUDENCE AND PHILOSOPHY OF LAW 278 (2004) (hereafter Greenawalt, Constitutional and Statutory Interpretation).

219. See supra section VI.C.5 on the incorporation of other speakers' meaning. See also SOLAN, LANGUAGE OF STATUTES, supra note 205, at 96 (" legislators do not generally think much about small details, understanding that these have been delegated to a small group of members.... [and it] serves no democratic function to require the courts to pretend otherwise by ignoring this aspect of the legislative process.")

220. See Sinclair, supra note 206, at 1388.

221. See generally Lloyd, supra note 5. See also Lloyd, supra note 27, at 24450 .

222. See Lloyd, supra note 27, at 244-50.

223. See Sinclair, supra note 206, at 1387-88. 
To do this, if we ultimately find either that (1) speaker meaning is mixed or inconsistent in unworkable ways, or (2) meaning simply cannot otherwise be ascertained, rule of law requires such an honest conclusion after a genuine and thorough inquiry. Turning to construction in either case does not involve an improper "triumph of non-elective law making." In either such case, we attempted to find workable speaker meaning, and, in its absence, we necessarily turn to the judicial branch which is charged with resolving disputes about meaning and the effects of such meaning. Additionally, construction as proposed in section VI.C.4 respects speaker meaning to the extent set out in such a proposed approach.

\section{v. Killing "Monarchs"}

All that said, we should not underestimate the power of context in resolving otherwise indiscernible legislator meaning even in the absence of legislative history. For example, one can imagine a statute that simply reads "monarchs can only be killed in the month of June" and includes no definition of "monarch." One can also imagine that all the legislators involved are dead, and that no legislative history for the statute survives. Does the statute permit regicides in the month of June or does it address something else?

In the absence of a definition of "monarch" in the statute and in the absence of any legislative history, we can still look at relevant other contexts. If, for example, all legislators swore to uphold the laws of the land and these laws forbade murder, it is difficult to see how "monarch" could plausibly mean "king" or "queen." This would be all the more true if such legislators operated in a system with a king or queen as head of state who would not assent to such legislation.

We can also look at still other contexts. Imagine, for example, that the statute was passed at a time when newspapers and other nonlegislative historical records note the near unanimous consent among the public that insects should be protected from extinction and that limiting the hunting of monarch butterflies to the month of June was imperative to that insect's survival. Given that context alone, interpreting "monarch" as the monarch butterfly could be quite defensible. Of course, we could have other conflicting contexts. For example, newspapers might also speak of endangered monarch beetles known only in that jurisdiction which should also only be hunted in the month of June if they are to be preserved. If exhausting all relevant contexts cannot resolve the butterfly/beetle quandary, then construction must step in and determine meaning and its legal effect (and perhaps conclude that "monarch" means both the butterfly and the beetle). Were this to occur, this would again show the importance of interpretation preceding construction. Interpretation removes the possibility of the 
statute's condoning murder and thus the possibility of its being construed as unenforceable on that ground.

\section{vi. Concepts versus Conceptions}

As a further caveat to the search for speaker meaning here, one must also recall the concept/conception distinction made in section VI.C.6 above. For example, in the statute regulating a "dozen" cakes, half of the legislators may have had conceptions of chocolate cakes while the other half may have had conceptions of vanilla cakes. In all such cases, however, they could have shared the same more general concept of "cake" as "a sweet baked food made from a dough or thick batter usually containing flour and sugar and often shortening, eggs, and a raising agent (such as baking powder)." 224 Thus, there would be no difference in legislator speaker meaning here despite the differing conceptions.

Additionally, the concept/conception distinction helps us avoid formulating and thus freezing meaning too narrowly. If all of the legislators had shared the conception of "cake" as chocolate cakes, it would be wrong to limit the meaning of the concept of cake only to chocolate cakes. Similarly, if all the legislators shared the same concept of firearm as a weapon that uses gunpowder to discharge its shot while at the same time also sharing the same conception of a firearm as a pistol, it would be wrong to limit such a concept to pistols. Thus, the Principle of Speaker Meaning is not misguided by forms of interpretation that might limit meaning to original conceptions. Further exploring how conceptions (and even concepts) can unfold over time, I also discuss in more detail the unfolding of sense though time in section VII.B below as well as the unfolding of reference through time in section VII.A below.

vii. Meanings as Used in the Legislative Process

Finally, one should also note that the Principle of Speaker Meaning seeks the legislators' concepts and conceptual frameworks public used in debates and other public legislative processes. It does not seek their secret motives, other secret desires, or other secret intentions. The Principle of Speaker Meaning is thus not plagued by questions involving such secret motives, other secret desires, or other secret intentions.

c. Scalia's Less-Tethered Hypothetical Directive Meaning

To put the integrity and strength of the Principle of Speaker Meaning in further context, Justice Scalia and his followers instead rely

224. See Cake, MERRIAM-WEBSTER's New ColLEgIATE DiCTIONARY (11th ed. 2014). 
purely on hypothetical constructs. Claiming that we are "governed by what the laws say, and not by what the people who drafted the laws intended," 225 Justice Scalia would, again, use his "reasonable reader", an "objectivizing construct," "who is aware of all the elements (such as the canons) bearing on the meaning of the text, and whose judgment regarding their effects is invariably sound. Never mind that no such person exists." 226

Of course, those concerned with improper judicial activism should worry about judges using such a hypothetical reader construct. Again, for the reasons discussed above in section VI.D.4.b.ii, rule of law cannot prioritize reader over legislative speaker meaning in statutory interpretation. ${ }^{227}$ Additionally, if we do not include the Principle of Speaker Meaning within "all the elements (such as the canons) bearing on the meaning of the text," we increase judicial interpretive discretion. We do that by ignoring restraints and suggestions of meaning provided by the Principle of Speaker Meaning. ${ }^{228}$

\section{Signs and Verdictives}

As another example of speech acts involving groups, I next explore whose meaning should control in verdictives (which again consist of such speech acts as convicting, acquitting, and fact finding). ${ }^{229}$ To do this, I explore a hypothetical jury that finds a defendant negligent in a slip and fall case and awards the plaintiff damages in the amount of $\$ 100,000$.

Although not an enduring entity like a legislature, the jury's group speech acts require a certain number of votes of members of the body. For example, the Federal Rules of Civil Procedure provide that "[u]nless the parties stipulate otherwise, the verdict must be unanimous and must be returned by a jury of at least [six] members." 230

For purposes of the example here, we can posit a jury of six persons in a civil case where a majority rather than a unanimous verdict is re-

225. See SCALIA \& GARNER, supra note 1 , at 375.

226. Id. at 393.

227. See Sinclair, supra note 206, at 1388.

228. To continue with "monarch" statutes, one can imagine, for example, a statute that simply reads "monarchs are banned." Imagine also that the only reference to what "monarchs" means is in the legislative history, and resort to legislative history is banned. See SCALIA \& GARNER, supra note 1, at 388 ("use of legislative history is not just wrong; it violates constitutional requirements of nondelegability, bicameralism, presidential participation, and the supremacy of judicial interpretation in deciding the case presented"). A "reasonable reader" here might therefore read that term as referring to either butterflies or kings. Such an approach no doubt leaves much more room for "judicial activism" here than the approach of the Principle of Speaker Meaning - at least where reliance on legislative history is banned.

229. AUSTIN, supra note 131, at 153.

230. FED. R. CIV. P. 48(b). 
quired. After several days of deliberation, the jury, by a vote of five to one, finds a defendant drugstore negligent in a slip and fall case and awards the plaintiff damages in the amount of $\$ 100,000$. One of the jurors did not think the drugstore was negligent. Although five of the jurors found the drugstore negligent, none of them individually initially thought $\$ 100,000$ was the proper damage amount. They each had different amounts in mind but finally compromised on $\$ 100,000$ as a fair amount.

On these facts, the jury's (not the jurors') verdictive speech act is the determination that the defendant was negligent and that the grant to the plaintiff should be a damage award of $\$ 100,000$. This verdictive speech act is not some sum of the individual intents or acts of six separate jurors (or of the subset of five who voted in favor of the verdict). Instead, it is the verdictive speech act of the jury as a separate entity, which speech act occurs because the requisite majority of jurors voted to find liability and to award damages in the compromise amount of $\$ 100,000$, an amount differing from the amount individual jurors would have awarded without need of compromise.

However, as with legislators in the legislative examples above, that is not to say that individual jurors' meanings, statements and purposes are irrelevant to the interpretation and construction of the group verdict. Similar to the meaning of legislative speech acts discussed above, the meaning of the jury's speech act is the meaning of the verdict debated by the jurors and approved by the requisite number of votes. Also similar to the case of legislative speech acts, meanings used by the jurors control the linguistic meaning of the verdict. If the jurors' meaning did not control, they could not have had a meaningful debate since they would have nonsensically debated meanings other than the ones they debated. Additionally, if their meanings did not control, rule of law would be subverted by use of meaning from those other than the jurors empowered to render a verdict.

Thus, to underscore the role of the jurors' meaning, the jurors can be polled to confirm each juror's vote. 231 If, for example, a tired foreman erroneously left a zero off the jury's verdict form and filled out the verdict form with the sum " $\$ 10,000$ " rather than " $\$ 100,000$," the jury can be polled to verify the award amount. ${ }^{232}$ In such a case, the jurors' intent for " $\$ 10,000$ " to mean one hundred thousand dollars should of course be controlling. Additionally, turning from interpretation to construction, if, for example, the dissenting juror has evidence that the five voted against the drugstore because they were bribed, the dissent-

231. FED. R. CIV. P. 48(c).

232. See FED. R. CIV. P. 49(b)(3) (addressing "Answers Inconsistent with the Verdict"); FED. R. CIV. P. 49(b)(4) (addressing "Answers Inconsistent with Each Other and the Verdict"). 
ing juror should of course be heard in considering whether the verdict should be construed as unlawful. ${ }^{233}$

When reading the jury's verdict form, there should therefore be little question that the Principle of Speaker Meaning should control here as a matter of interpretation. We can reasonably discern both the jurors' identity and their intent as to the verdict the majority approved. Reader meaning, on the other hand, might find an erroneous "plain meaning" of $\$ 10,000$ unless the reader was aware of the actual jurors' meaning and factored that meaning into interpretation. But would this not return us to the jury's speaker meaning as understood by the jurors? The Principle of Speaker Meaning thus soundly directs us to the actual verdictive speech act as understood by the actual jurors.

\section{MEANing AND Time: Signs, ORIGINALISM, AND the FiXATion OF MEANing Debate}

Having addressed multiple aspects of the semiotics of meaning, we can now briefly turn to the semiotics of meaning and time. Even though meaning is not transcendentally fixed, ${ }^{234}$ there remains the question of whether meaning somehow becomes fixed within our webs of signs at the time such meaning is first signified. For example, Justice Scalia's version of the "fixed-meaning canon" holds "that words must be given the meaning they had when the text was adopted." 235 To address claims of fixation, we must first distinguish between the reference and the sense component of meaning and provide an answer for each.

\section{A. Time and Reference of Signs}

With respect to the reference component of meaning within our webs of signs, in many cases, we can consider fixation the default (but only the default) position, even though such reference is not transcendentally fixed. If, for example, we say that a lawyer gave a speech on March 14 , 2019, we would ordinarily say reference to the speech itself remains fixed within our discourse even though we may from time to time reach different conclusions as to what was meant by that speech. That is, we might debate the meaning of the speech over time but we would ordinarily say that we are referring within our discourse to the same speech.

However, though fixation is thus the initial default with reference, we can nonetheless say that reference can and should change in cer-

233. See, e.g., FED. R. EVID. 606(b)(2)(B) (permitting jurors to testify regarding, whether "an outside influence was improperly brought to bear on any juror").

234. See supra section II.B.

235. See SCALIA \& GARNER, supra note 1 , at 428. 
tain situations within our discourse. For example, if we learn that $\mathrm{X}$ rather than $\mathrm{Y}$ was the first person to write a treatise on the interpretation of contracts, we will thus change the reference of the phrase "the first person to write a treatise on contracts" from Y to X. Since reference is not transcendentally fixed, ${ }^{236}$ we can make such correction. Thus, reference can be refined or changed by refining definite descriptions as discussed above in section II.B.1.a.

\section{B. Time, Sense, and the Meaning of Signs}

For at least the four reasons discussed below, fixation of sense claims are at best tautological and at worst erroneous. First, since sense is the total actual and possibly-conceivable ways in which notions unfold or can unfold in experience, 237 "freezing" or fixing such sense at best simply "fixes" such sense as such possible as well as actual unfoldings in ever-unfolding and ever-changing experience. Such a "fixation" thus hardly rules out possibilities of sense changing as experience always continues to unfold. ${ }^{238}$

Second, since meaning plays out in ever-changing experience, such experience itself brings its own changes to the unfolding of meaning. We now, for example, must debate whether "marriage" in an older statute includes same-sex marriage given the social and legal changes in the concept of marriage. Marriage now means something very different today 239 than it meant when only members of the opposite sex could marry, when women were belittled by coverture, ${ }^{240}$ or when many heterosexual blacks were barred from the institution entirely as slaves. ${ }^{241}$ Thus, we also now see such definitions of marriage as "[a] legal union between two persons that confers certain privileges and entails certain obligations of each person to the other, formerly restricted

236. See supra section II.B.1.a. Although reference is not transcendentally fixed, it does provide stability in the rule of law. Taking again our butterfly statute that provides "monarchs are banned," the sense of "monarch" cannot shift through time to mean "royal head of state" without a corresponding change in the reference. Such unlinking a statute from one referent and linking it to a radically different referent no doubt requires appropriate state action if we are to have rule of law. Again, this is not to say that the sense, understanding, or both of monarch cannot unfold over time. We can discover new colors of the monarch; we can come to see the monarch as no longer endangered; we can come to see the monarch in new symbolic ways, etc. See infra section VII.B.

237. See supra section II.B.2.a.

238. As explored supra Part VI, we could non-tautologically speak of affixation of meaning such as whose meaning should we affix to certain signs.

239. See Obergefell v. Hodges, 576 U.S. 644 (2015).

240. See generally. Amber Bailey, Comment, Redefining Marriage: How the Institution of Marriage Has Changed to Make Room for Same-Sex Couples, 27 WIS. J.L. GENDER \& SOC'Y 305 (2012).

241. See generally Darlene C. Goring, The History of Slave Marriage in the United States, 39 J. MARSHALL L. REV.299 (2006). 
in the United States to a union between a woman and a man". ${ }^{242}$ This definition notes how the concept of marriage has unfolded through time by highlighting the removal of a once-necessary element: a union of those of the opposite sex. ${ }^{243}$ Consistent with this unfolding of the concept of marriage through time, Peirce eloquently and presciently tells us that:

A symbol [such as a word], once in being, spreads among the peoples. In use and in experience, its meaning grows. Such words as force, law, wealth, marriage, bear for us very different meanings from those they bore to our barbarous ancestors. ${ }^{244}$

Third, precedent presents an obvious legal example of such experiential change. A court's determination of statutory meaning is legally binding so long as the precedent lasts or until the legislature amends the statute to provide other meaning. ${ }^{245}$ Precedent thus broadly presents problems for any alleged fixation of meaning unless perhaps one considers the possibility of "relying on precedents" as part of the original meaning. But if "relying on precedents" is part of the original meaning, this would reaffirm that the meaning is not fixed but can change as precedent requires. ${ }^{246}$

Fourth, such fixation claims are wrong to the extent they ignore the fact that speakers can actually intend for their concepts to unfold over time. For example, legislation may involve open-ended terms such as "reasonable" or "unfair" which "invite the court to provide meaning."247 Additionally, a group of legislators, for example, could intend that a statutory concept of "marriage" for which they vote should evolve in accordance with less-discriminatory lay concepts of marriage that unfold over time.

242. Marriage, THE AMERICAN HERITAGE DICTIONARY OF THE ENGLISH LANGUAGE (5th ed. 2016) (emphasis added).

243. See id.

244. 1 \& 2 PEIRCE, supra note 7 , at 2.300. As Blake also powerfully notes: "Reason, or the ratio of all we have already known, is not the same that it shall be when we know more." WILLIAM BLAKE, There is No Natural Religion, in POEMS AND PROPHECIES 4 (Alfred A. Knopf 1991).

245. See, e.g., 21 C.J.S. Courts $§ 183$ (2020) ("The doctrine of "stare decisis" incorporates two principles: (1) a court is bound by its own prior legal decisions unless there are substantial reasons to abandon a decision; and (2) a legal decision rendered by a court will be followed by all courts inferior to it in the legal system .") See also $i d$. \$ 220 ("An even more extraordinary and compelling justification is needed to overturn precedents involving statutory interpretation because unlike in constitutional cases, if the precedent or precedents have misinterpreted the legislative intention embodied in a statute, the legislature's competency to correct the misinterpretation is readily at hand.")

246. See, e.g., Greenawalt, supra note 154, at 55-56.

247. See, e.g. POPKIN, supra note 212, at 203. See also Greenawalt, Constitutional and Statutory Interpretation, supra note 218, at 275 ("Legislatures adopt some provisions with open-ended phrases that definitely envision that those who apply the law will make judgments consonant with changing circumstances.") 
Furthermore, where the purpose of a statute is to govern future behavior, would it not be reasonable to imagine that those involved in the passage of the statute assumed (unless perhaps they tried to include a fixation clause along the lines discussed below in this section VII.B) that meanings of the statute would unfold in sensible ways in such future experience?

One can also, of course, give countless lay examples of such intended unfolding of sense. If I write a letter to a friend telling him that he is always welcome at "my house," it would not make sense in such an endless invitation for the meaning of "my house" to be frozen as of the time of writing. I am not inviting my friend to a house frozen in time beyond reach but to a house that exists in time and thus changes in physical and other ways, including social ways. As social standards (such as desirability and price), for example, unfold over time, understandings of "my house" will unfold accordingly in those regards as well.

Finally, even at one point in time, one cannot know all the possible conceptions of a concept that might exist-though one can and should know this limitation of one's knowledge. Thus, we can share the same concept of cake at a given point in time despite infinite possible conceptions of cakes of various tastes, colors, shapes, and so on, none of which excludes the others from falling under the concept of cake.

In light of all these points, we can return briefly to Justice Scalia's version of the "fixed-meaning canon" which, again, provides "that words must be given the meaning they had when the text was adopted."248 Could we perhaps make more sense of Justice Scalia's canon by modifying it to apply only to statutes which expressly include a "freezing" or fixation clause such as: "terms used in this statute shall have the meanings in effect as of the date of passage of this statute"? Even ignoring how we should handle the specific phrase "meaning in effect" (whose meaning? does "meaning" here mean conception rather than concept?), it is hard to see how such a modification would work. First, we have the problem with precedent discussed above. Second, we cannot comprehend such "frozen" meanings apart from how they actually and possibly play out in ever-unfolding and ever-changing experience. Third, the meaning of the fixation clause itself (as with all other meaning) would unfold over time. But to say all this, of course, is to say such meanings are not fixed except perhaps, again, in the tautological sense that the meanings involved are the meanings involved. But, again, meaning consists of possible as well as actual unfoldings in ever-

248. SCALIA \& GARNER, supra note 1, at 428. Justice Scalia does, for example, temper this canon with such provisos as his "principle of interrelating canons" ("No canon of interpretation is absolute. Each may be overcome by the strength of differing principles that point in other directions") and his recognition that "general terms may embrace later technological innovations." Id. at 59, 16 . 
unfolding and ever-changing experience. Such a tautology thus hardly rules out possibilities of meaning changing as experience always continues to unfold

\section{Time and Application of Signs}

Those who would "freeze" or fix meaning 249 might try to respond that applications or extensions of concepts change rather than the concepts themselves. For example, such persons might maintain that the original concept of marriage above has not changed but that instead we now have new "extensions" or "applications" of the term "marriage." Such persons might claim that marriage is a general concept that does not purport to name every person, place, thing, or event to which the concepts possibly extend. ${ }^{250}$ They might claim that such general concepts give us the "criteria" or other guidance we need to determine what specific things or events are included within the concepts; for example, the concept of "green" gives us the "criteria" or other guidance we need to pick out actual green things in the world. ${ }^{251}$ Those who would "freeze" or fix meaning might thus attempt to parse between concepts (which do not change) and applications of those concepts, where applications may include applications not contemplated at the time of a statute's passage.

The unfolding of the concept of marriage through time, however, involves change to the very criteria of what constitutes marriage. Where a union of members of the opposite sex was an original element of the concept of marriage, ${ }^{252}$ current application of the concept of marriage to same-sex parties would be impossible without a change in the very concept of marriage that eliminates the opposite-sex requirement. Additionally, again, the meaning of the "criteria" given by concepts for application of such concepts cannot be fully fixed since we cannot comprehend "frozen" meanings outside of the very time and unfolding of experience required to comprehend and apply them at any point in time.

In saying this, however, I do not deny that we apply concepts. Judicial opinions, for example, of course apply concepts when such opinions apply rules to the case at hand. However, such application is necessarily performed in the context of then-unfolding experience, which experi-

249. See, e.g., SCALIA \& GARNER, supra note 1, at 435 ("A legal text should be interpreted through the historical ascertainment of the meaning that it would have conveyed to a fully informed observer at the time when the text first took effect."). Of course, would not a fully informed observer at any time know that concepts can unfold over time in unforeseen directions?

250. As Michael Sinclair notes, "[a] legislature cannot normally enact extensions; they would be simply too particular." Sinclair, supra note 206, at 1370 .

251. See, e.g., id. at 1358.

252. Marriage, THE AMERICAN HERITAGE DICTIONARY OF THE ENGLISH LANGUAGE (5th ed. 2016). 
ence bears the marks of prior experience to date. Additionally, I fully acknowledge the importance of application since sense itself unfolds through experience, and application involves such unfolding of sense. One cannot therefore have a reasonable grasp of concepts apart from reasonably grasping such unfolding of meaning through appropriate application. Thus, Gadamer can correctly say that "[a]pplication does not mean first understanding a given universal in itself and then afterward applying it to a concrete case. It is the very understanding of the universal-the text-itself." 253 For the fullest sense of "understanding," I would therefore agree with Gadamer that "understanding always involves applying the meaning understood." 254 If sense unfolds through experience, how could we say otherwise? ${ }^{255}$ This point is magnified by the fact that sense is determined by context, ${ }^{256}$ and that the sense of context, like other sense, also unfolds through experience. ${ }^{257}$ However, in addition to the unfolding of meaning through time by the applications of concepts through time, I would be clear that concepts themselves (as with the case of marriage above) can evolve through time in ways that change application itself.

\section{Time and Signifier Drift}

In addition to such evolving meaning of the signified through time, signifiers can also refer to different or additional signifieds over time. For example, the Middle English verbal signifier for a road was "rode" 258 though the signifier "rode" now signifies the past tense of "ride." Such signifier drift through time is often used as a primary ar-

253. GADAMER, supra note 98, at 336. I would also agree that "[i]t is only in all its applications that the law becomes concrete. Thus the legal historian cannot be content to take the original application of the law as determining its original meaning." Id. at 322 .

254. Id. at 328. I thus also agree with Gadamer that "application is neither a subsequent nor merely an occasional part of the phenomenon of understanding, but co-determines it as a whole from the beginning." Id. at 321.

255. Cf. 1 \& 2 PEIRCE, supra note 7, at 1.219 ("What I mean by the idea's conferring existence upon the individual members of the class is that it confers upon them the power of working out results in this world, that it confers upon them, that is to say, organic existence, or, in one word, life.").

256. See SCALIA \& GARNER, supra note 1 , at xxvii ("Nothing but conventions and contexts cause a symbol or sound to convey a particular idea.").

257. As I am not dealing with pragmatics in detail in this Article, I will not also explore problems finding "fixed" sense that result from any differences in experience and understanding of an author and a reader. See, e.g., 5 \& 6 PEIRCE, supra note 6, at 5.506 (discussing the imprecision flowing from the fact that "no man's interpretation of words is based on exactly the same experiences as any other man's"); GADAMER, supra note 98, at 272 ("The recognition that all understanding inevitably involves some prejudice gives the hermeneutical problem its real thrust.").

258. See Road, MERRIAM-WEBSTER's NEW COLLEGIATE DICTIONARY (9th ed. 1983). 
gument by originalists: we must, the argument goes, be originalists to avoid confusion in light of such signifier drift. ${ }^{259}$

This argument, however, does not address the fact that the signified (such as the meaning of the word "marriage") can unfold over time as well. Instead, this argument focuses on the different case of signifier drift. If the signifier " $\mathrm{X}$ " signified the concept A when used in a statute but now signifies the concept $B$, we must of course recognize that the original statute signifies the concept $A$ rather than the concept $B$. However, this does not mean that we should ignore the ways the concepts A and B themselves unfold over time.

Confusing signifier drift with the unfolding of concepts through time thus risks conflating the signifier with the signified (and we might add that fallacy to the list of logical fallacies lawyers should avoid). That we must now, for example, interpret the Middle English "rode" as $\operatorname{road}^{260}$ when applying a Middle English "rode" statute is logically distinct from the fact that the concept of a road can unfold through time. Similarly, interpreting Shakespeare's use of "Marry" in an original archaic sense of expressing "indignant surprise" 261 where appropriate is logically distinct from the fact that the concept of marrying or marriage can unfold over time. Thus, judges and lawmakers can recognize that sense unfolds over time in the way discussed above. ${ }^{262}$ Signifier drift categorically differs from the unfolding of the sense of concepts, and a careful semiotics avoids conflating the two. ${ }^{263}$

\section{Some Brief Closing Thoughts on FiRst Amendment Semiotics}

Grappling with the signifier, the signified, whose meaning should control in various situations, and correlations between the signifier and a signified can also help refine free-speech analysis. Although deep explorations of semiotics and free speech are beyond the scope of this introductory Article on semiotics and the law, I can outline a few remarks on the subject. These remarks presume reasons commonly given for protecting speech: protecting democracy and our right to selfgovernance, ${ }^{264}$ permitting "the search for knowledge and 'truth' in the marketplace of ideas," 265 protecting "individual autonomy, selfexpression, or self-fulfillment," 266 and fostering tolerance. ${ }^{267}$

259. See SCALIA \& GARNER, supra note 1, at 78, 82 (discussing what Queen Anne may once have meant by "awful, artificial, and amusing").

260. See Road, MERRIAM-WEBSTER's NEW COLLEGIATE DICTIONARY (9th ed. 1983).

261. See ALEXANDER SCHMIDT, SHAKESPEARE LEXICON AND QUOTATION DICTIONARY 696 (3d ed. Dover 1971).

262. See supra section VII.B.

263. See SCALIA \& GARNER, supra note 1 , at 78, 82 .

264. See generally James Weinstein, Participatory Democracy as the Central Value of American Free Speech Doctrine, 97 VA. L. REV. 491 (2011).

265. Id. at 502 (setting forth the rationale while contending that "a com- 


\section{A. Freedom of Speech and Signifier Types}

Good First Amendment jurisprudence recognizes that words are not the only signifiers of expression. The American flag, for example, is no doubt a symbol of America, and burning that flag can therefore symbolize, for example, disapproval of America or American policy. If so intended, flag burning can thus be symbolic expression despite Chief Justice Rehnquist's general claim that "flag burning is the equivalent of an inarticulate grunt or roar that, it seems fair to say, is most likely to be indulged in not to express any particular idea, but to antagonize others." 268 Of course, burning a flag can also be non-symbolic where there is no expressive intent. Burning a flag, for example, can be a proper means of flag disposal and need express nothing beyond the desire to dispose of a flag properly. ${ }^{269}$ Or, on the other hand, by virtue of proper disposal, such flag burning might be seen as great respect for the flag itself or the country it represents.

\section{B. Freedom of Speech and Harmful Signifiers}

However, it does not follow from the fact that anything can serve as a signifier that all things are fair game for signifiers and free expression as a matter of law. Again, trademark law protects a "word, phrase, logo, or other sensory symbol used by a manufacturer or seller to distinguish its products or services from those of others;" 270 copyright law protects "an original work of authorship . . . fixed in any tangible medium of expression," ${ }^{271}$ and criminal law would not permit killing a public official as a signifier of political protest. ${ }^{272}$ In each of these cas-

pletely unregulated market of ideas will lead to discovery of truth is highly contestable").

266. Id. at 502-04; Brian C. Murchison, Speech and the Self-Realization Value, 33 HARV. C.R.-C.L. L. REV. 443, 498-503 (1998) (". . . First Amendment analysis [should] attend more self-consciously to the speaker's development through expression.").

267. Lee C. Bollinger, The Tolerant Society: A Response to Critics, 90 COLUM. L. REV. 979, 984-85 (1990).

268. Texas v. Johnson, 491 U.S. 397, 432 (1989) (Rehnquist, C.J., dissenting).

269. 4 U.S.C. $\$ 8(\mathrm{k})$. See also Johnson, 491 U.S. at 411 (stating that federal law holds burning to be the preferred means of disposing of a flag that is no longer fit for display).

270. Trademark, BLACK's LAW DICTIONARY (7th ed. 1999) (also noting that "[i]n effect, the trademark is the commercial substitute for one's signature").

271. Copyright, BLACK'S LAW DICTIONARY (7th ed. 1999). One might by copyright analogy justify, as a matter of construction, prohibitions against protestors disrupting for political expression a funeral designed by others to convey a message of sorrow and good remembrance. I have explored other rationales for such restrictions elsewhere. See generally Harold A. Lloyd, Crushing Animals and Crashing Funerals: The Semiotics of Free Expression, 12 FIRST AMEND. L. REV. 237 (2013).

272. See NAACP v. Claiborne Hardware Co., 458 U.S. 886, 916 (1982) ("The

First Amendment does not protect violence."); United States v. Stevens, 559

U.S. 460, 493 (2010) (Alito, J., dissenting) ("The First Amendment protects 
es, freedom of speech analysis must balance the harm of violence to rights or to persons against any harm of limiting expression. Exploring such a balance in detail is beyond the scope of this Article. However, I can address below the potential fungibility of signifiers as one available balancing tool in certain cases.

\section{Freedom of Speech and Fungible Signifiers}

\section{Draft Cards}

If a non-harmful signifier can signify just as well as a harmful one, a good grasp of semiotics supports balancing interests and requiring use of the non-harmful signifier rather than the harmful signifier. Using the non-harmful signifier, the speaker speaks just as clearly, and harm to others is avoided. For example, if burning an excellent copy of a draft card conveys the same sense of protest to unwitting viewers conveyed by burning an actual draft card, where is the free-speech need to damage an official document such as a draft card?273

\section{Cookies}

Continuing to balance harms, we can also imagine a cookie baker who offers his famous and easily-identifiable cookies for retail sale, who claims that his cookies are his works of art celebrating heterosexuality and condemning homosexuality, who has made his views on sexual orientation well known, and who therefore refuses to sell his cookies to gay customers. ${ }^{274}$ In other words, he claims his cookies are signifiers for expressive (if not also assertive) speech acts. ${ }^{275}$ Given that anything can be a signifier, this sort of example is of great importance if we worry that freedom of speech may be used as cover for discrimination or other pernicious purposes.

freedom of speech, but it most certainly does not protect violent criminal conduct, even if engaged in for expressive purposes."); United States v. Mullet, 868 F. Supp. 2d 618, 623 (N.D. Ohio 2012) ("The First Amendment has never been construed to protect acts of violence against another individual, regardless of the motivation or belief of the perpetrator."). I have also written elsewhere on restrictions on using living beings as signifiers. See Lloyd, supra note 271 , at $244-45,282-83$.

273. Discussing this iconic option would have bolstered the Court's decision upholding a draft card mutilation statute in United States v. O'Brien, 391 U.S. 367 (1968). Though modern color photocopying technology would be easy to make an exact duplicate for burning, prior to such technology, a folded piece of paper or one in an envelope, for example, could perhaps have passed as the real card before an audience.

274. Due to space limitations, I discuss this simpler case of the cookie baker who refuses to sell to gay customers. I hope to do a future article on the semiotics of Masterpiece Cakeshop, Ltd. v. Colo. Civil Rights Comm'n, 138 S. Ct. 1719 (2018) (involving a wedding cake baker who refused to sell a wedding cake to a gay couple).

275. See supra section V.A. 
Signifier fungibility can provide an answer here as well. The cookie baker can choose other signifiers that at least equally convey his celebration of heterosexuality and his condemnation of homosexuality, signifiers that in fact might convey such celebration and condemnation more precisely. For example, putting his thoughts and rationales to words can perhaps express them more clearly than would such unconventional signifiers as cookies. If so, requiring other fungible signifiers would thus not require discrimination against gay customers while still permitting the baker's free (and perhaps more precise) expression.

If other fungible signifiers exist for his message (including words which may be more precise means of expression), how would prohibiting discriminatory cookie sales on the level of signifier analysis (1) infringe on the baker's right to speak on matters of public concern; (2) interfere with the battle of truth in the marketplace of ideas; (3) endanger his right to "self-expression;" or (4) improperly (after balancing the harm of discrimination against the fungibility of signifiers) circumscribe his autonomy and self-fulfillment as a matter of expression?276

\section{Jackets}

Of course, where signifiers are not so reasonably fungible, such lack of reasonable fungibility can support the use of such signifiers where, for example, harm to others does not outweigh use of such signifiers. An excellent example of such lack of fungibility would be signifiers uniquely conveying emotional meaning, such as Mr. Cohen's "Fuck the Draft" jacket worn in the corridors of the Los Angeles County Courthouse in $1968 .{ }^{277}$

\section{Freedom of Speech and Correlation of the Signifier and the Signified}

Notwithstanding the reasoning above, however, might the cookie baker above reasonably argue that some sort of objectionable compelled expression occurs if he must sell his cookies to gay people?

\section{Symbolic Concerns}

If the cookie baker uses his cookies to celebrate heterosexuality and condemn homosexuality, does compelling him to sell his cookies for use at a gay celebration compel him to express a contrary message? If his

276. See supra notes 264-67 and accompanying text on reasons for free speech protection.

277. See generally Cohen v. California, 403 U.S. 15 (1971). In that case, Mr. Cohen used that phrase to express publicly "... the depth of his feelings against the Vietnam War and the draft." Id. at $1 \dot{6}$. 
cookies are used at such a celebration, do they not now convey celebration rather than condemnation?

Semiotics helps us see how no compelled expression exists here for at least two reasons. First, under the Principle of Speaker Meaning, the cookie baker's meaning is unimpaired. The baker's cookies are famous, easily recognizable, and his views are well known. Second, signifiers can be put to non-expressive use without impairing the speaker's meaning. For example, I can use a treatise as a doorstop without impairing or changing the speaker's meaning. Similarly, a gay celebration can put out cookies solely for purposes of refreshment without impairing or changing the speaker's meaning. As such, again, one cannot reasonably claim that the sale of cookies to gay people endangers the baker's right to speak on matters of public concern, interferes with the battle of truth in the marketplace of ideas, endangers the baker's right to self-expression, or circumscribes his autonomy, self-expression, and self-fulfillment as a matter of expression. 278

\section{Additional Indexical Concerns}

Apart from the meaning the baker attaches to his cookies, if his cookies are used at a gay celebration and everyone at the celebration is aware that the cookies came from his bakery, does this physical connection with the celebration in itself not indicate either celebration of homosexuality or, at the very least, the baker's involvement with, and thus approval of, a sexual orientation he condemns? In asking such a question, we are in fact asking at least two indexical questions.

First, we are asking whether the baker's mere physical connection through the sale itself indicates views disavowed by the baker. This is not a difficult question. On the purely transactional level, a retailer simply sells his goods, and the acceptance of the price and tender of the goods therefore simply indicate such a sale. There seems little more to be said on this point of pure logic.

However, we must also ask whether sale of the cookies could also indicate mental attitudes of the baker. For example, an individual's donation to a political party may reasonably indicate support of that party (although it can indicate other things such as desire to gain favor). Though mental states can be thus indicated, it is hard to find indexical expression here of mental states supporting the gay party or anything gay at all. Again, the baker is in a retail business and thus presumably sells cookies to many whose views he rejects. It is hard to see how the default state of mind indicated here is anything more than simply a retail one. Should one have any doubt, the baker's views on homosexuality are well-known and should thus clarify any such doubts.

278. See supra notes 264-67 and accompanying text on reasons for free speech protection. 
Thus, one cannot reasonably claim that any indexical meaning of the sale of cookies to gay people endangers the baker's right to speak on matters of public concern, interferes with the battle of truth in the marketplace of ideas, endangers the baker's right to self-expression, or circumscribes his individual autonomy, self-expression, and selffulfillment. ${ }^{279}$

Due to space limitations, I must end my First Amendment comments here. I hope, however, to see others probe such semiotics- including courts - as they wrestle with the extent and limits of freedom of speech.

\section{Conclusion: Semiotics AND the Middle Path}

Having now examined the utility and insights of semiotics for those involved in legal theory, practice, and education, I end by first pointing out two opposing paths that one might wrongly take after an exploration of semiotics. I then end by noting a sensible semiotics that threads between such opposing erroneous paths.

Since signifiers can effectively include any concrete, abstract, tangible, or intangible thing (such as any "concrete object," "abstract entity," "idea or "thought," "object perceptible," "physical event," or "imaginable" object, ${ }^{280}$ and since meaning is not transcendentally given, ${ }^{281}$ one must carefully gauge one's reaction to that vastness of potential signifiers and their potential signifieds.

Taking such care, one must not abandon all restraint and believe that one can assert, direct, commit, declare, or express 282 anything as signified with anything as signifier. As I have written before, both semantic and pre-semantic experience would push back against such unlimited license. ${ }^{283}$ For example, if one steals a trademark, directs actions with words that no one can comprehend, or claims to a police officer that "stop" means "go," one may well experience failure or loss. Additionally, one must take care that the vastness of potential signifiers is not used as "free speech" cover for unlawful or harmful behavior when, for example, other reasonably fungible signifiers exist, or when semiotic analysis otherwise exposes such cover as mere cover.

All that said, one must not cower in the face of that vastness of potential signifiers and signifieds by seeking comfort in wrong beliefs ${ }^{284}$

279. See supra notes 264-67 and accompanying text on reasons for free speech protection.

280. NÖTH, supra note 8, at 80. 1 \& 2 PEIRCE, supra note 7 , at 2.230.

281. See supra section II.B.1.

282. See supra Part V (discussing the various types of speech (semiotic) acts).

283. Lloyd, supra note 27, at 222-50.

284. See id. at 210-22 (describing various freedoms we have in, for example, framing, creating meaning, and adjusting categories). 
in formalism (i.e., in beliefs that the law is "a self-contained system of legal reasoning" involving deduction of neutral and apolitical results from "general principles and analogies among cases and doctrines" 285 ). Again, since referents and sense are not transcendentally given, and since reality is "internal" to our semantic lifeworlds, ${ }^{286}$ we can always have hope of seeking change where progress requires. Additionally, since sense itself unfolds in experience over time, one cannot speak of the law in any meaningful way as a "self-contained" system severed from such unfolding of sense in experience over time.

Unlike the approaches above, a sensible semiotics must by definition actually work. ${ }^{287}$ It must take a middle path between (1) formalism lost in a "self-contained" system, impossibly severed from the unfolding of sense in experience, and (2) any semiotics of unlimited license. Semiotics shows us that such a middle path must also be a "hermeneutic" path, i.e., a path involving interpretation. One cannot workably address what one does not comprehend. To comprehend, one must have workable notions of both meaning and interpretation, which allow one to "present [something] in understandable terms" and "to explain or tell the meaning of [that something]." 288 I have therefore called this middle path "hermeneutic pragmatism" to reflect both the required pragmatism and the required understanding of meaning and interpretation. ${ }^{289}$ In this middle path, in this sensible semiotics, in this hermeneutic pragmatism lies law's soundest way to achieving sensible and ever-unfolding justice and rule of law.

285. See MorTon J. HorWitz, THE TRANSFormation of AMERICAN LAW 1870-1960: THE CRISIS OF LEGAL ORTHODOXY 16 (1992) (defining formalism). 286. See PUTNAM, supra note 33, at 114 ("the internal realist ... is willing to think of reference as internal to 'texts' (or theories), provided we recognize that there are better and worse 'texts.' 'Better' and 'worse' may themselves depend on our historical situation and our purposes; there is no notion of a God's-Eye View of Truth here.); Lloyd, supra note 27, at 210-22, 232-34.

287. I have addressed workability in detail elsewhere. See Lloyd, supra note 27 , at $264-71$.

288. Interpret, MERRIAM-WEBSTER'S NEW COLLEGIATE DICTIONARY (11th ed. 2014).

289. See Lloyd, supra note 27, at 201. 


\section{APPENDIX \\ Some Further Useful Terms and Concepts}

\section{Three Subdivisions of Semiotics}

Charles Morris classically provides a useful definition of three subdivisions of semiotics: pragmatics, semantics, and syntactics.

Pragmatics "is that portion of semiotic which deals with the origin, uses, and effects of signs within the behavior in which they occur." 290 Understanding pragmatics as the study of how individuals in actual practice use words and other signs, I have written about the subject elsewhere and will not explore in detail many of the matters I have previously addressed. ${ }^{291}$ Pragmatics is, of course, an extremely important subdivision of semiotics for lawyers. Much of what we do involves how a particular person or entity used language, such as struggling with what they meant by a word or words which they used.

Semantics "deals with the signification of signs in all modes of signifying," and syntactics "deals with combinations of signs without regard for their specific significations or their relation to the behavior in which they occur."292 This Article explores semantics to the extent it explores the signified but does not explore syntactics. ${ }^{293}$

\section{Semiosis versus Semiology and Tokens versus Types}

To help readers as they explore semiotics further, I note here three distinctions readers will likely encounter.

First is the distinction between "semiotics" and "semiosis." "Semiosis" is "the process of meaning-making"; this includes meaning-making involved in the interaction of the signified and signifier. ${ }^{294}$ The term also refers to "signification as a process" or "the activity of signs" 295 and "the process of sign interpretation." 296 It can also mean "any sign action or sign process" or "activity of a sign." 297

290. CHARLES MORRIS, Signs, LANGUAGE AND BEHAVIOR 219 (1946).

291. See generally Lloyd, supra note 5.

292. MORRIS, supra note 290, at 219.

293. Nöth describes the three branches as follows using "sign vehicle" for "signifier": syntactics "studies the relation between a given sign vehicle and other sign vehicles," semantics "studies the relations between sign vehicles and their designata," and pragmatics "studies the relation between sign vehicles and their interpreters." NÖTH, supra note 8, at 50.

294. See CHANDLER, supra note 44, at 259 (referring in Peircean fashion to the signifier as "representamen" and the signified as "the object and the interpretant").

295. Semiosis, ENCYCLOPEDIA OF SEMIOTICs (Paul Bouissac ed., 1998).

296. Short, supra note 74, at 105.

297. VinCENT M. COLAPIETRO, GLOSSARY OF SEMIOTICS 178 (1993) (bolding omitted). 
Second is the distinction readers may see between "semiotics" (referring to work within the tradition of Charles Sanders Peirce, which tradition this Article follows) and "semiology" (referring to work within the tradition of Ferdinand de Saussure). ${ }^{298}$ Saussure's views ${ }^{299}$ are generally beyond the scope of this paper, which again follows the tradition of Peirce.

Third is the distinction between tokens and types. As Nöth puts it, "A sign in its singular occurrence is a token, whereas the sign as a general law or rule underlying its use is a type." 300 Taking the word "fast" as an example: "As a word of the English language it is a type. Every written or spoken instance of that is a token." 301 Thus, if a paragraph uses the word "contract" four times, there will be four tokens of the English-language word.

\section{Signs and Lifeworlds}

Lawyers exploring semiotics in any depth will encounter the terms Lebenswelt (or lifeworld), Umwelt, and Innenwelt. Although the first of these three terms is likely familiar to many lawyers, I will briefly address all three terms. Assuming that language shapes experience, ${ }^{302}$ I favor Putnam's definition of the "lifeworld" or "Lebenswelt" as "the world as we actually experience it." 303 As I would define the term, such a lifeworld includes both the technical as well as the nontechnical. ${ }^{304}$ It

298. See CHANDLER, supra note 44, at 259.

299. Saussure took a synchronic approach to semiotics, studying "a phenomenon (such as a code) as if it were frozen at one moment in time." Id. at 262. Consistent with this, he distinguished between (1) "langue" as an "abstract system of rules and conventions of a signifying system [that] is independent of, and pre-exist, individual users" and (2) "parole," which "refers to concrete instances of [language's] use." Id. at 252. As I see semiotics and language as living (even though they carry potentially challengeable traditions and readymade concepts and schemas), I therefore see Saussure's approach as quite wrong.

300. NÖTH, supra note 8 , at 81.

301. Id.

302. I agree with Rorty that: "The world is out there, but descriptions of the world are not. Only descriptions of the world can be true or false. The world, on its own-unaided by the describing activities of human beings - cannot." RICHARD RORTY, CONTINGENCY, IRONY, AND SOLIDARITY 5 (1989). Similarly, Gadamer claims that language is "the all-embracing form of the constitution of the world" and on language "depends the fact that man has a world at all." GADAMER, supra note 98 , at 440.

303. See PUTNAM, supra note 33, at 118. Lacking the space to give an extensive history of the use of this term, I would briefly point back to Husserl. Smith gives useful definitions in Husserl's context: "Lebenswelt" is "the lifeworld, the world of everyday life, the surrounding world as experienced in everyday life" and "life-world" is "the surrounding world as experienced in, everyday life, including "spiritual' or cultural, that is, social, activities." DAVID WOODRUFF SMITH, HUSSERL 437 (2007).

304. See CHAÏM PERELMAN \& L. OLBRECHTS-TYTECA, THE NEW RHETORIC: A TREATISE ON ARGUMENTATION 99 (John Wilkinson \& Purcell Weaver trans., 1969). (explaining that beside other linguistic beliefs lie "agreements that are peculiar to the members of a particular discipline, whether it be of scientific 
includes interpretive groups that are "nested" within others; thus, the American legal community, for example, "is surrounded by the political community, the social community, and ultimately the entire interpretive community of American and perhaps international culture." 305 Lifeworlds are therefore complex webs of meaning where change generally requires justifications acceptable to the appropriate members of the nested communities. ${ }^{306}$ For example, competent lawyer-members of such complex webs will push back on claims that "due process" is a meaningless term.

"Umwelt" is "[t]he environment selectively reconstituted and organized according to the specific needs and interests of the individual organism." 307 Put another way, "Umwelt" is the "environment insofar as an organism is equipped to perceive it" and is thus "not simply what is objectively there, but only what is perceptually and operationally available to the organism." 308 As to the relation of Umwelt to Lebenswelt, Deely notes "the specifically human Umwelt" is called by some the Lebenswelt. ${ }^{309}$

According to Deely, the Umwelt "depends upon and corresponds to an Innenwelt." 110 An Innenwelt is a "cognitive map, developed within each individual" that "enables the individual to find its way in the environment and insert itself into a network of communication, interest, and livelihood shareable especially with the several other individuals of its own kind." 311

\section{Charity and Related Notions}

Consistent with rational interaction, the Principle of Speaker Meaning assumes that speakers acting in good faith wish to speak relevantly in the speech situation at hand. ${ }^{312}$ That is, they assume that speakers acting in good faith by definition wish to speak in a way that "can

or technical, juridical or theological nature. Such agreements constitute the body of a science or technique").

305. BENSON, supra note 142, at 74. Thus, Benson also describes Stanley Fish's notion 'that we all live in 'interpretive communities' which are made up of a 'political, social and institutional ... mix' of constraints on acceptable interpretations." Id. See also PERELMAN \& OLBRECHTS-TYTECA, supra note 295 , at 513 ("All language is the language of a community, be this a community bound by biological ties, or by the practice of a common discipline or technique. The terms used, their meaning, their definition, can only be understood in the context of the habits, ways of thought, methods, external circumstances, and traditions known to the users of those terms.").

306. See PERELMAN \& OLBRECHTS-TYTECA, supra note 295, at 513 ("A deviation from usage requires justification ....").

307. DEELY, supra note 49, at 59-60.

308. COLAPIETRO, supra note 288, at 201.

309. DEELY, supra note 49 , at 60 .

310. Id.

311. Id.

312. See PAUl Grice, Studies In The WAY OF Words 27 (1989). 
be interpreted as contributing to the conversational [or other] goals" of the speaker or hearer. ${ }^{313}$ Consistent with this, the Principle of Speaker Meaning assumes that, if a speaker wishes to be relevant, she by definition would not generally intend to speak wrongly, irrationally, or incoherently, even if her words or other signs could be interpreted as wrong, irrational, or incoherent. ${ }^{314}$ This leads us to a principle of balance or charity that generally infers a rational and coherent meaning unless we have reasons to believe otherwise. ${ }^{315}$

\section{The Pre-Socratics to Peirce: Semeion, Symbolum, Signum, and Icon}

Semiotics has an ancient pedigree. Tracing its lines in simplest of terms, one can note the ancient Greek fascination with the indexical. Pre-Socratics such as Parmenides and Heraclitus understood the Greek term "semeion," or sign, in the sense of evidence, or "tekmerion," which explains why Hippocrates focused on symptoms as signs of diseases. ${ }^{316}$ In addition to this indexical understanding of "semeion" (whose paradigm "was a medical symptom" such as "spots"), 317 one also encounters "symbolos" used for sentences and words. ${ }^{318}$ Both the index and the symbol securely fell under the umbrella of "sign" once St. Augustine famously used "signum" to include "both the evidential signs of the Greeks and words as linguistic signs used in communication." 319 Further filling out sign types, St. Bonaventura and others explored iconic signs. ${ }^{320}$ Peirce designed his subsequent "classification of signs into icons, indices, and symbols ... to incorporate the principal types of signs discussed in the tradition he inherited." 321 Thus, lawyers who use and appreciate semiotics today stand on the shoulders of giants from

313. CRUSE, supra note 131, at 419 (quoting G. N. LEECH, PRINCIPLES OF PRAGMATICS (1983)).

314. See DONALD DAVIDSON, INQUIRIES INTO TRUTH AND INTERPRETATION 27 (1984); RESTATEMENT (SECOND) OF CONTRACTS § 203(a) (AM. LAW INST. 1981) ("[A]n interpretation which gives a reasonable, lawful, and effective meaning to all the terms is preferred to an interpretation which leaves a part unreasonable, unlawful, or of no effect.").

315. As Kent Greenawalt nicely tells us: "What I would hope from an interpreter [who has found statements that seem contradictory or at odds with the remainder of a piece] is that if she could figure out which statement did fit my overall position best and which reflected a lapse in how I have expressed myself, she would say, "Greenawalt probably means X (or would think X) though one of his sentences points in a different direction." KENT GREENAWALT, LEGAL INTERPRETATION: PERSPECTIVES FROM OTHER DISCIPLINES AND PRIVATE TEXTS 82 (2010).

316. See ClARKE, supra note 10, at 2-3, 11-13.

317. COLAPIETROA, supra note 297, at 177-78

318. ClARKE, supra note 10, at 3. But see COLAPIETROA, supra note 297, at 177-78 (noting that "this distinction between sign and symbol was in ancient Greek usage not always clearly or consistently drawn"). It is beyond the scope of this work to explore whether, for example, passages of Aristotle may have used "symbola" and "semeia" interchangeably. See id. at 15.

319. CLARKE, supra note 10, at 3, 23.

320. Id. at 4-5, 34-35, 41-43.

321. Id. at 5. 
the pre-Socratics to Peirce and beyond. Unfortunately, I lack space to explore historical semiotics in more detail here, but hope this summary will entice readers to explore more such history on their own. ${ }^{322}$

322. Those who are especially ambitious may wish to start with JOHN DEELY, FOUR AGES OF UNDERSTANDING: THE FIRST POSTMODERN SURVEY OF PHILOSOPHY FROM ANCIENT TIMES TO THE TURN OF THE TWENTY-FIRST CENTURY (Marcel Danesi et al. eds., Univ: of Toronto Press 2001). This tome explores "preliminaries to the notion of sign; the development of the notion itself; forgetfulness of the notion; and recovery and advance of the notion" in the long history of Western philosophy. Id. at xxx. 